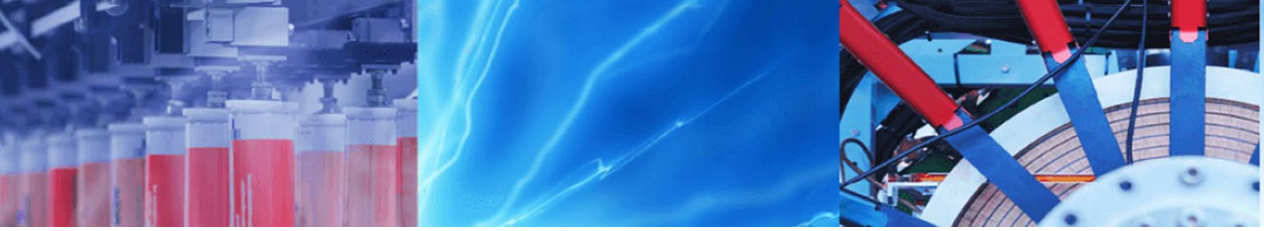

Research Article

\title{
Modification in gate valve using flexible membrane pipe for flow measurement
}

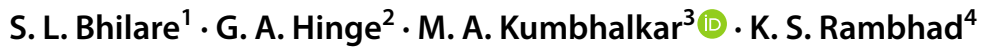

Received: 18 May 2021 / Accepted: 11 October 2021

Published online: 03 November 2021

(c) The Author(s) 2021 OPEN

\begin{abstract}
A gate valve is used to regulate discharge in pipelines. It is rotated by a wheel that is attached to a circular disc (i.e. gate) at the top of a stem. Each revolution of the wheel creates a particular linear disc movement that changes the flow zone. The paper describes the journey of gate valve from flow control device to flow measuring device and presents an experimentation on conventional gate valve and gate valve with flexible membrane pipe. The findings of experimental study are described and validated with CFD analysis of conventional and modified gate valve. The experimental study has shown that the modified gate valve can be used as flow measuring device. The results obtained represent the excellent improvement in the relationship between disc position (i.e., angle) and discharge. The results of CFD analysis for flow through gate valve with and without flexible membrane are compared. After carrying out the CFD studies without flexible membrane, it is found that, fluctuating separation zones formed on either side of gate are responsible to a great extent to the flow rate descripancies. This paper compares the experimental and CFD results and also suggests the remedy to address the problem.
\end{abstract}

\section{Article highlights}

- Introduced simply a flexible membrane pipe inside PVC to convert gate valve into flow measuring device.

- Reduction in flow separation and fluctuation in flow rate.

- Smooth flow rate even though gate valve opening is small.

Keywords Gate valve · Separation zone · Flow measuring device · Flexible membrane pipe $\cdot$ CFD

\section{Introduction}

Flow metres are devices that measure the rate at which gas, liquid, or steam flows through a pipe. Water flow are just a few of the applications that require mass flow monitoring. A gate valve is commonly used for many household and industrial applications. Many industrial applications demand accurate flow control for various processes [1-3].

$\triangle$ M. A. Kumbhalkar, manoj.kumbhalkar@rediffmail.com; S. L. Bhilare, bhilare_sudhir@yahoo.com; G. A. Hinge, gahinde777@ gmail.com; K. S. Rambhad, kishorsrambhad@gmail.com | ${ }^{1}$ Department of Civil Engineering, JSPM's Rajarshi Shahu College of Engineering and Research, Pune 411037, India. ${ }^{2}$ Department of Civil Engineering, TSSM's Bhivarabai Sawant College of Engineering and Research, Pune 411041 , India. ${ }^{3}$ Department of Mechanical Engineering, JSPM Narhe Technical Campus, Pune 411041, India. ${ }^{4}$ Department of Mechanical Engineering, St. John College of Engineering and Management, Palghar 411404, India. 
Fig. 1 Gate Valve with its components at closed and open condition
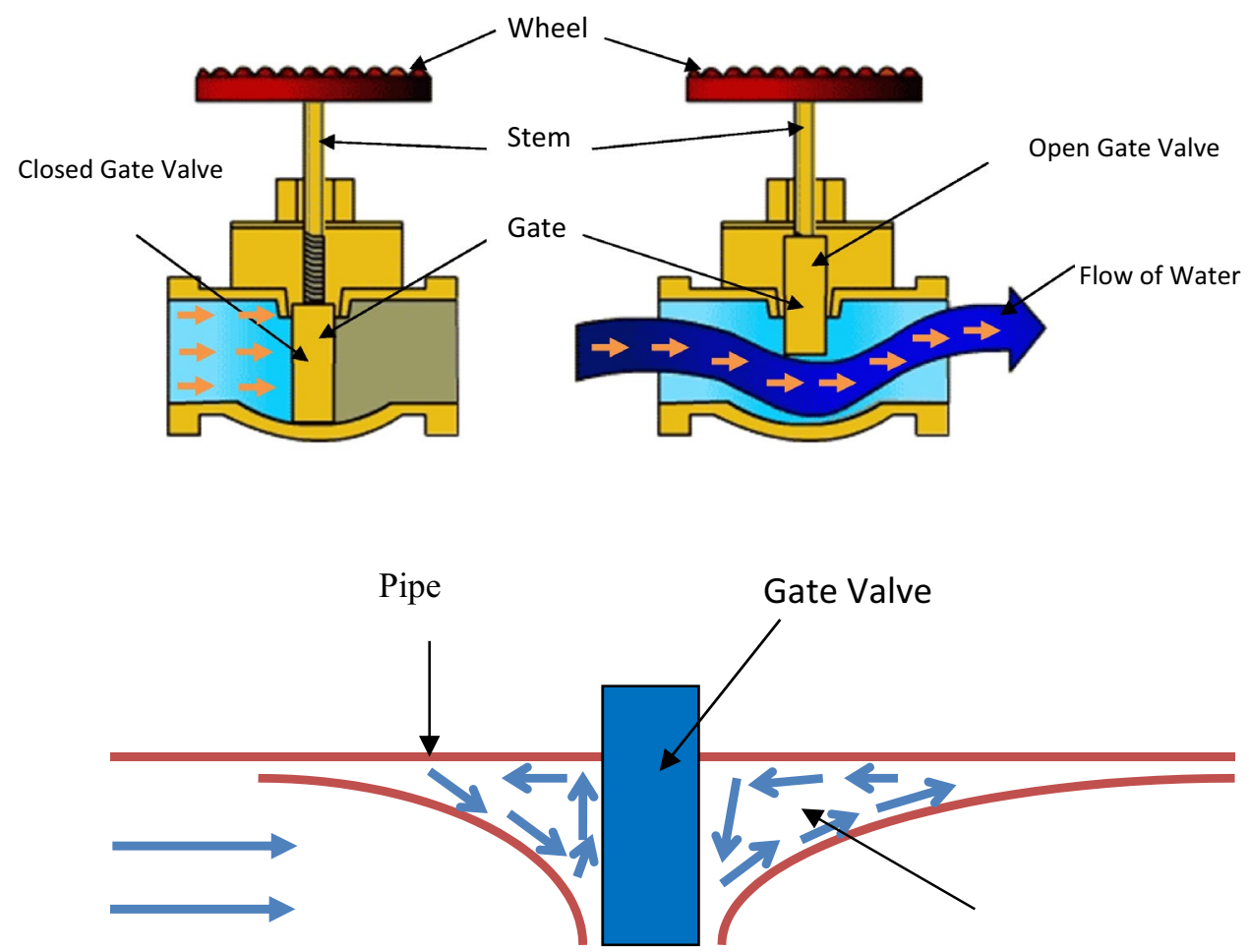

Flow Direction

Separation Zone
In fact, the gate valve itself is a flow control device. But on account of its inability to precisely control the flow, it needs to be supplemented with a separate flow measuring device. Therefore, gate valves, when used along with some flow measuring device like 'Venturi meter' or 'Orifice Meter", can act as precise flow control devices [4-6]. Figure 1 shows the gate valve and its components. In this study, the gate valve was successfully tested as a flow measuring device for a single operating condition.

\subsection{Mechanism of gate valve}

The wheel of the gate valve is connected to a circular disc by means of a stem. The clockwise and counterclockwise movements of the wheel result in linear movement of the gate in forward and backward directions, respectively.

As per 'Control Valve Handbook', gate valves are used for on/off service and are designed to operate fully open or fully closed. Because of excessive vibrations created in partially-closed gates, the valves are not intended for throttling or flow regulation [7].

Zakirnichnaya and Kulsharipov [8] captured the velocity vector plot on either side of the gate valve, which shows the formation of separation zones and reverse flow therein.
Also, Steele et al. [9] measured the force exerted on the stem at different gate positions. They have also reported that this force keeps on fluctuating continuously [8].

Bhilare and Hinge [10] have carried out experiments with a $65 \mathrm{~mm}$ gate valve to find out the relationship between the rotation angle of the wheel and the discharge. It was reported that no exact relation could be established between these two parameters owing to the formation of fluctuating separation zones on either side of the gate [10].

Rambhad et al. [11] performed CFD analysis for checking the flow pattern with and without inserts in the pipe. Zhelin et al. performed $2 \mathrm{D}$ gate valves with various relative openings. The CFD-DEM method was used to study gas-solid flow and particle erosion. Relative opening has a significant effect on gas flow and particle distribution. The number of particles plays an important role in erosion. Erosion of the cavity is more serious than that of the flashboard [12]. Palau et al. demonstrated the significance of proper metre placement and how flow disruption affects the registered measurement of water consumption in irrigation regions. The suggested simplified approach for error estimation has the potential to significantly decrease the high cost of experimental testing [13].

Figure 2 shows a schematic of the separation zones which tend to form on either side of the gate. As the 
separation zones keep on fluctuating, it affects the coefficient of discharge, which also keeps on changing over a period of time and results in discharge variation for the same gate position.

The present study attempts to convert a gate valve into a flow measuring device by rotating the wheel in an anti-clockwise/clockwise direction based on its capacity to increase or decrease flow. After carrying out experimentation on a $65 \mathrm{~mm}$ gate valve in the fluid mechanics laboratory, it was observed that the relationship between the rotation angle of the wheel and discharge is not perfect. To address this issue, it is proposed to use a flexible membrane pipe inside the gate valve. This membrane will prevent the separation zones from forming, as its shape will automatically adapt depending upon the disc position and the intensity of discharge. It acts as a venturi metre with dynamically changing convergent and divergent sections. With this new adaptation, an experimental setup is fabricated with a $65 \mathrm{~mm}$ acrylic pipe and tested.

This study contains experiments on conventional and modified valves, as well as a comparison of the two, as well as a CFD analysis of the conventional and modified valves to check for flow separation. In the conclusion, comparative research is offered along with a full discussion. The conclusion, and also the paper's future scope, is offered at the end.

\section{Experimental setup}

\section{A. Experiments on conventional gate valve}

To experimentally investigate the flow conditions, an experimental setup with a recirculation system was fabricated. It included a pipeline with a traditional gate valve. The inflow was taken from the overhead tank under a constant head of $1.83 \mathrm{~m}$. For the experimental model, various trials were taken to measure discharge for the same gate position of the valve and corresponding rotation angles were recorded.

Figure 3 a shows the schematic of the experimental setup, and Fig. $3 \mathrm{~b}$ shows the actual setup with a conventional gate valve. The discharge was measured on a volumetric basis. While carrying out the tests with a conventional gate valve, the fluctuating separation zones were observed. The modified gate valve can be used as a flow measuring device (e. g. in a laboratory) as well as a flow control device (e. g. in industry). While using it for any of the above-mentioned purposes, the calibration would be with respect to the corresponding supply head. If the supply head changes, then the calibration equation will also change accordingly.

For the conventional model, a $65 \mathrm{~mm}$ metallic gate valve was taken. Complete closing of this valve requires 13 rotations of the wheel, which results in an angular measure of 46,800 . Before fixing the valve, points at 900 intervals are marked along the periphery of the bonnet of the valve. On both the sides of the valve, an acrylic pipe of length equal to the flow development length (i.e., $650 \mathrm{~mm}$ ) was provided. The transparency of the acrylic pipe helped to observe the flow conditions. For the remaining portion, a non-transparent PVC pipe was used. Hence, the total length of the horizontal pipe of the experimental setup was $6 \mathrm{~m}$.

The experiments were started with a completely open valve and measured the corresponding discharge. Then it was partially closed by rotating it in a clockwise manner through an angular interval of $90^{\circ}$, and the discharge was measured. The same procedure was repeated until the valve was closed up to 8 rotations. On a similar line, the readings were taken while opening the valve at an interval of $90^{\circ}$ by rotating the wheel in an anticlockwise direction. This completed one set of readings. 2-sets of such readings were taken. It was noticed from Fig. 4 that, for the same angular position of the wheel, the discharge was not the same. This has given an indication of the problem associated with the traditional gate valve. Due to flow separation that occurs in the conventional gate valve, very high fluctuations are recorded in the flow rate.

\section{B. Experiments on gate valve with flexible membrane pipe}

Another model with identical parameters was fabricated by putting an additional flexible membrane pipe inside the gate valve, as shown in Fig. $5 a$. Figure $5 \mathrm{~b}$ shows the schematic of the modified shape of the flexible pipe inside the gate valve as a response to the position of the gate. The purpose of using flexible pipe was to avoid the formation of separation zones. Figure $5 c$ shows the actual experimental setup with a close-up view of the transparent acrylic pipe with a flexible pipe duly modified.

This system consists of a $65 \mathrm{~mm}$ gate valve fixed along the acrylic pipe on either side, having a flow development length of $650 \mathrm{~mm}$. This flexible pipe was fabricated with rubber material which is used in cars as a mat sheet.

Length of flexible pipe was $=$ Flow development length on either side + length of valve

$$
\begin{aligned}
& =(650+650)+228.6 \\
& =1528.6 \mathrm{~mm}
\end{aligned}
$$




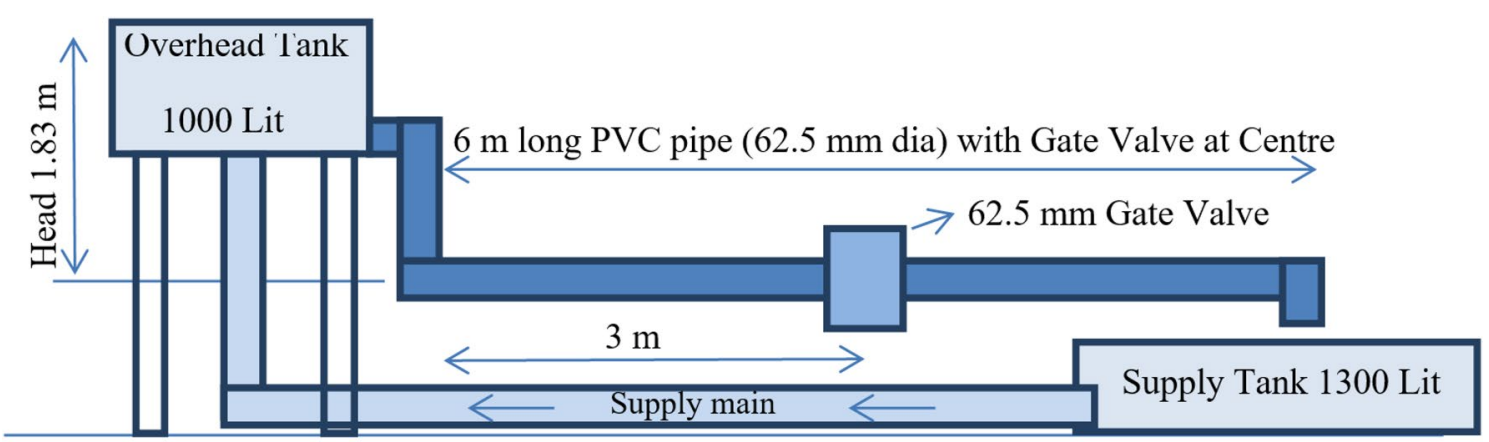

(a)

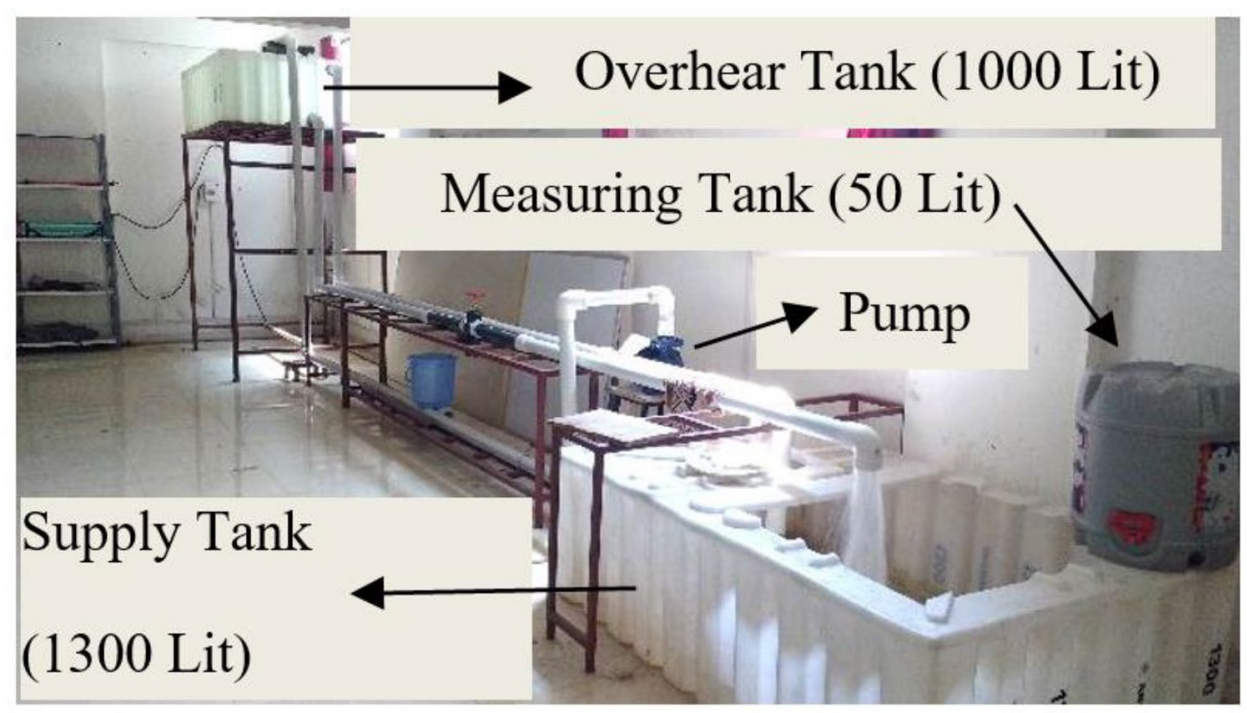

(b)

Fig. 3 a Schematic of experimental setup [3]. b Experimental setup of convention and modified gate valve setup [3]

Fig. 4 Discharge through conventional gate valve at an interval of $90^{\circ}$ rotation angle in clockwise and anticlockwise direction

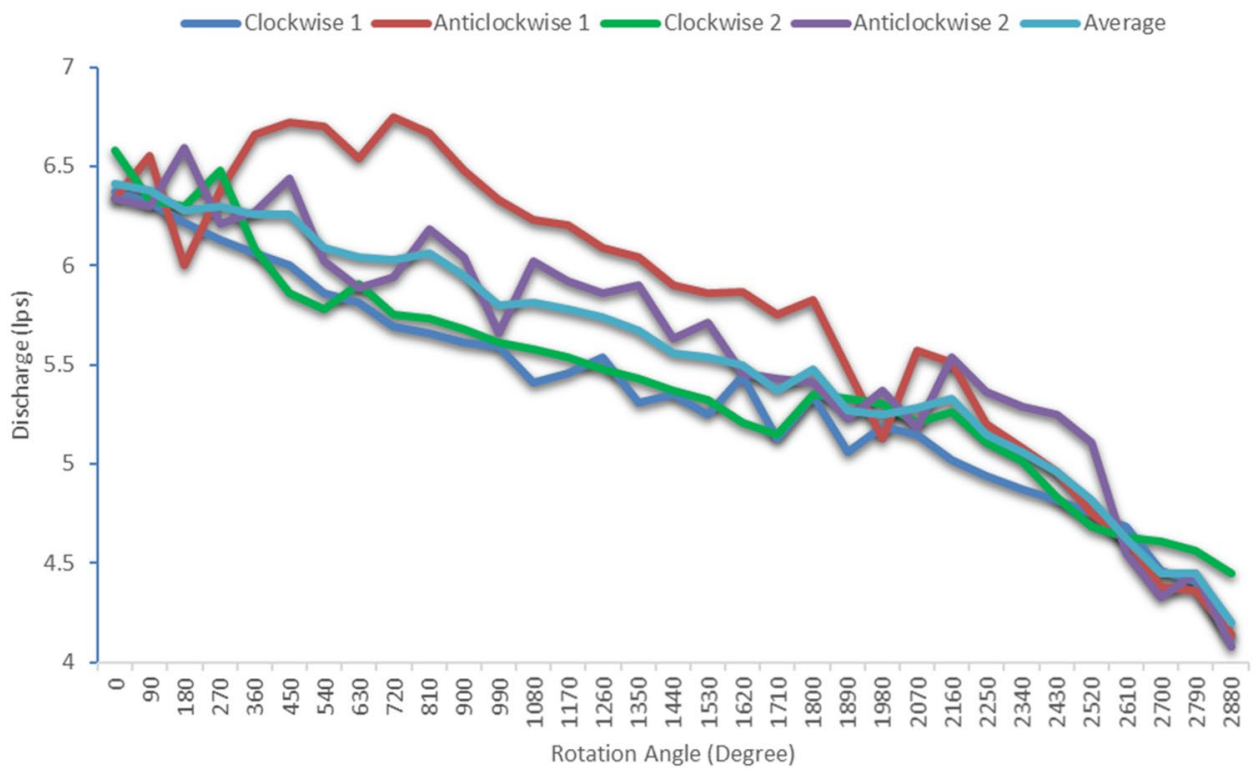




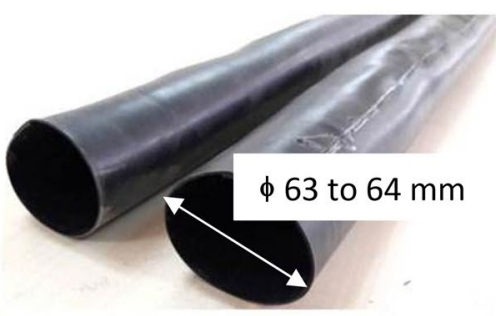

(a)

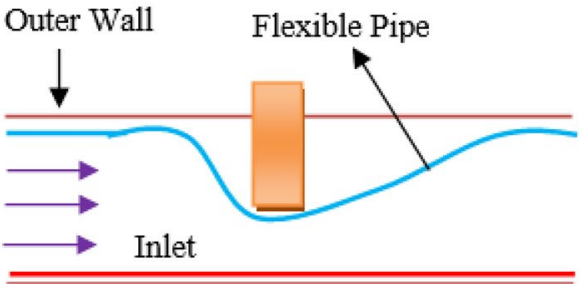

(b)

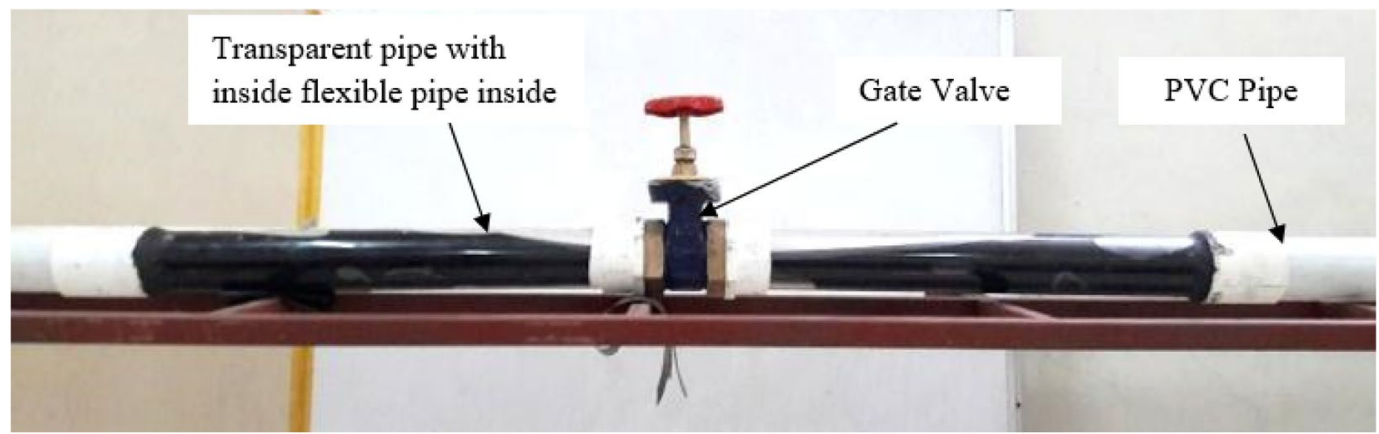

(c)

Fig. 5 a Flexible rubber membrane pipe. b Schematic of flexible pipe inside gate valve. $\mathbf{c}$ Actual flexible membrane pipe inside gate valve

As a result, a flexible pipe $1550 \mathrm{~mm}$ long was chosen. Initially, the transparent acrylic pipes were connected on either side of the gate valve. Then the flexible pipe was inserted inside this assembly. Due to the additional $100 \mathrm{~mm}$ length of flexible pipe, $50 \mathrm{~mm}$ of it came outside the ends of the acrylic pipes. This part of the flexible pipe was gently wrapped around the PVC pipe and the solution was applied to make it water tight. Further acrylic pipes were connected to PVC pipes.

The same procedure is followed for the recording of readings. Similar to the previous case, two sets of readings were taken in a clockwise and anticlockwise manner and are presented in Fig. 6 . It was observed that the discharge was almost the same for the same position of the gate valve.

\section{Findings of experimental study}

For each set of readings, graphs were drawn to analyse the results. On $\mathrm{X}$-axis angle of rotation of wheel in degree was taken while discharge was taken on $Y$-axis in litres per second.

Graphical presentation of readings taken for conventional Gate valve showed scattered pattern as discharge varied each time due to formation of fluctuating separation zones. Whereas in case of Gate valve with flexible pipe, the pattern observed was in close proximity. This showed that the relationship between gate position and discharge could be established.
Figure 7 depicts a comparison of discharge vs. wheel rotation angle for conventional and modified valves, for a total of two sets of readings. Figure 7a represents the first cycle of clockwise and anticlockwise running, and Fig. $7 \mathrm{~b}$ represents the second cycle of clockwise and anticlockwise running. For the same rotation angle, considerable variation in discharge in a conventional gate valve was observed in both cycles. The discharge fluctuations may be attributed to the fluctuating separation zones formed on either side of the gate. Whereas for the modified gate valve, the discharge fluctuations were considerably damped in both cycles.

After complete analysis of the results, it was observed that the use of flexible pipe has considerably improved the performance of the gate valve as a flow measuring device. The modified gate valve was calibrated and the linear equation was obtained by the method of best fit as given below.

$y=6.042-0.0005 x$

where $y$ : Discharge in liters per second, $x$ : Angle of Rotation in Degree.

The error between discharge estimated by equation and experimentation was found to be less than $\pm 2 \%$. Thus, a good agreement was found between the mathematical and experimental models. Whereas the maximum discharge variation in the case of a traditional gate valve was observed to be $12 \%$. 
Fig. 6 Discharge through modified gate valve at an interval of $90^{\circ}$ rotation angle in clockwise and anticlockwise direction

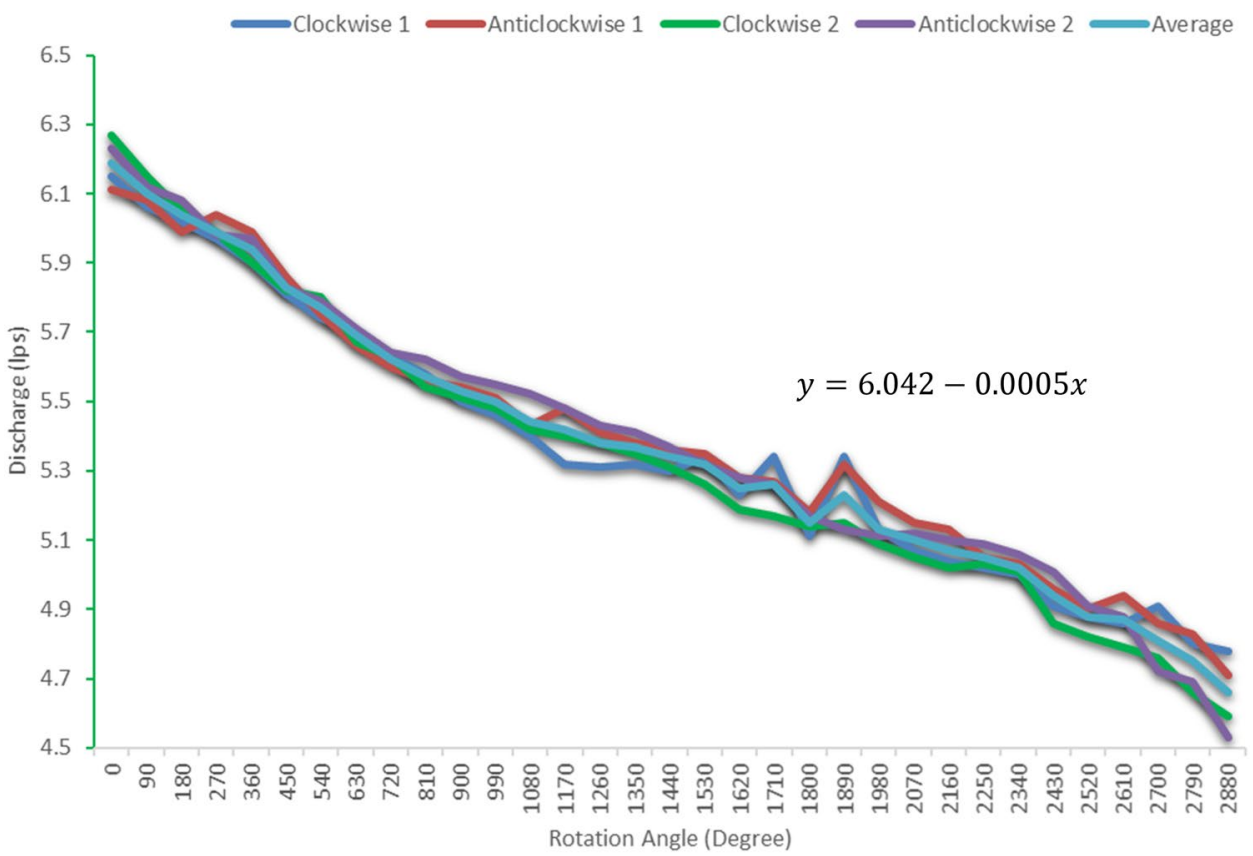

\section{CFD analysis of conventional and modified gate valve}

It is proposed to conduct a numerical study of the flow through a gate valve using computational fluid dynamics using ANSYS Fluent. The mass flow rate at the output of the pipe has been experimentally analysed using an experimental set up and the result is shown in Fig. 4. CFD analysis for flow through a pipe with a gate valve has been carried out and the results are validated with experimental results. For CFD analysis of flow through a pipe, five cases have been considered with different gate valve openings. Case V has been additionally considered for CFD analysis.

Case I Flow through pipe with a $100 \%$ open gate valve. Case II Flow through pipe with a $70 \%$ open gate valve Case III Flow through pipe with a $55 \%$ open gate valve Case IV Flow through pipe with $40 \%$ open gate valve Case V Flow through pipe with a $25 \%$ open gate valve

For CFD analysis, a $2 \mathrm{~m}$ long and $65 \mathrm{~mm}$ in diameter pipe has been considered for flow through pipe with a gate valve. A pipe is introduced with a gate valve $(10 \mathrm{~mm}$ thick gate) at the centre and is filled with liquid with the properties of water. Also, the model is meshed with SOLID 186 hexahedral elements with 67,891 nodes and 20,753 elements. While checking mesh performance, the maximum and total volume of mesh are considered as $2.358875 \mathrm{e}^{-06} \mathrm{~m}^{3}$ and $6.527024 \mathrm{e}^{-03} \mathrm{~m}^{3}$ respectively, and the maximum face area is considered as $2.260751 \mathrm{e}^{-04} \mathrm{~m}^{2}$.
The mesh quality has been evaluated with the maximum aspect ratio of $2.51885 \mathrm{e}^{+03}$. For improving poor quality cells, the worst $0.1 \%$ of cells are considered and identified as 470 cells (out of 21,077 ), $2.229919 \%$, with orthogonal quality below 0.000488 . Based on these meshing quality parameters, the element size is finalised as $100 \mathrm{~mm}$, for 20,753 total divisions of elements. A 3D model of the pipe is shown in Fig. 8, and a mesh model of the pipe with a liquid domain is shown in Fig. 9. The sweep meshing with a hexahedral element has been carried out for $100 \%$ of the open pipe, and multizone meshing is being carried out for the remaining cases. The input parameters are given in Table 1.

As a boundary condition, a mass flow rate is given as input at the inlet of the pipe with the SST k-omega turbulence model, and the mass flow rate is checked at the outlet of the pipe [14-16]. The flow of water through pipe and mass flow rate with various gate openings are shown in Fig. 10. From Fig. 10a, it is observed that the flow through pipe is linear with $100 \%$ gate valve opening. The flow of water is not linear at various other gate positions and changes due to the partial closing of the gate valve. It is observed that there is a reverse flow of water after passing through the gate valve. It is evident from Fig. 10a that the pattern of flow is symmetrical at $100 \%$ gate opening. Also, it is observed that the mass flow rate is constant after 30-40 iterations in all cases, and the mass flow rate at the inlet and outlet is equal. Further, similar analysis is done for the modified gate valve. While doing so, the average shape of the flexible pipe (captured from the experimental 


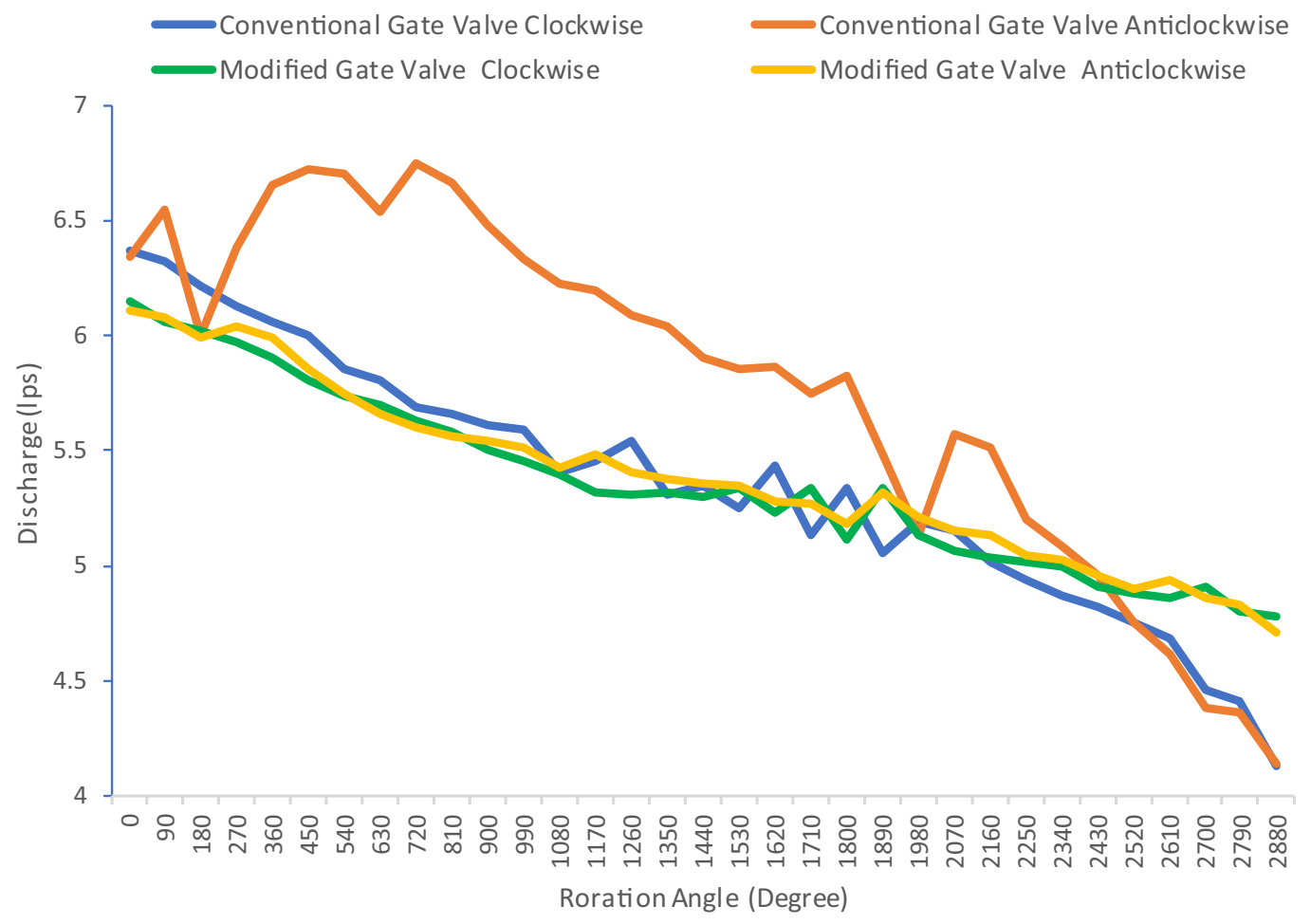

(a)

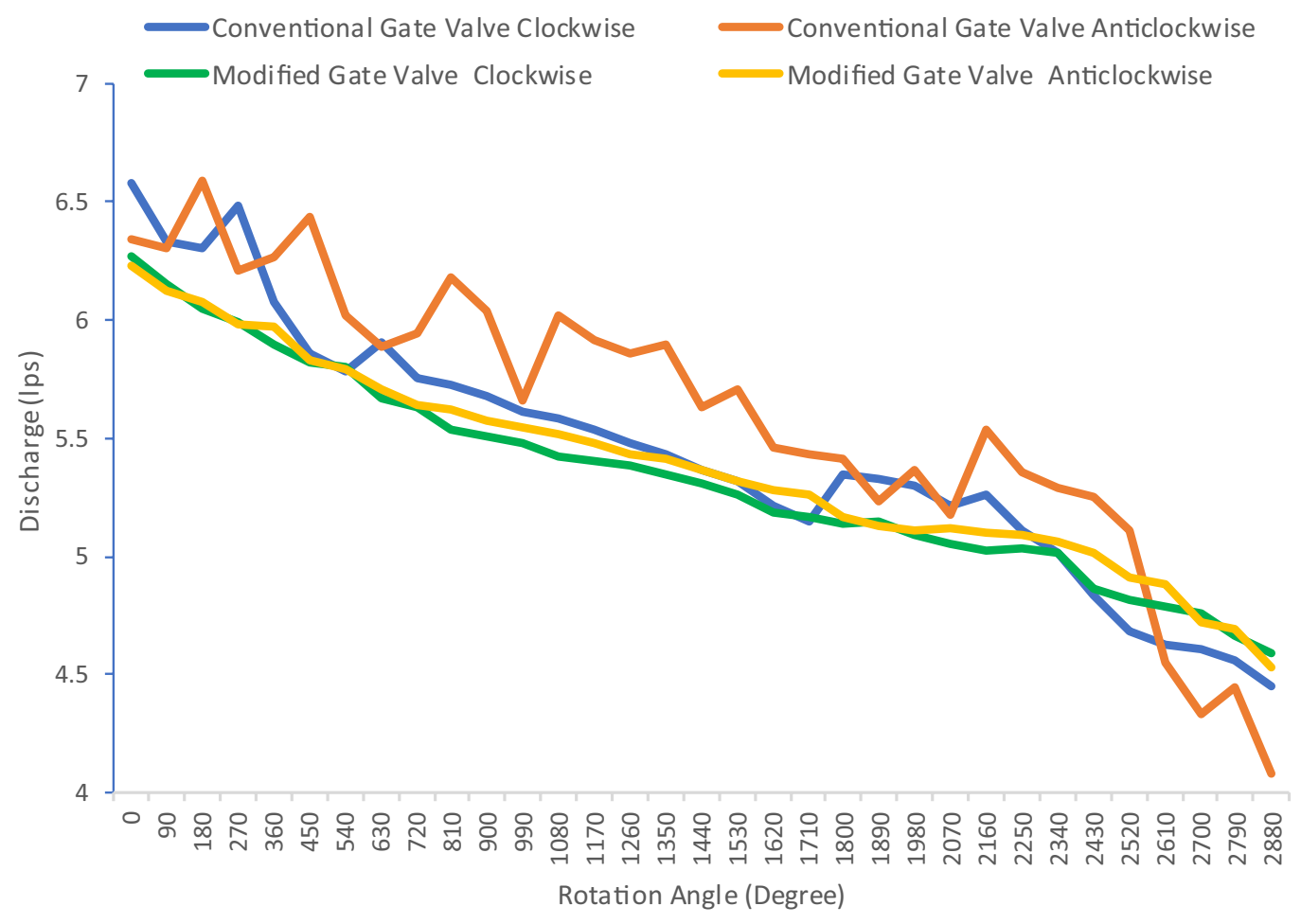

(b)

Fig. 7 Comparison of discharge through conventional and modified gate valve for both cases in clockwise and anticlockwise direction 
study pertaining to a specific gate opening) is reproduced in the rigid pipe. Figure 10b shows the symmetrical flow pattern for $70 \%, 55 \%$, and $40 \%$ gate openings. Also, as compared to a conventional gate valve, the turbulent fluctuations are found to be dampened. Thus, it also indicates that the velocity fluctuations are dampened to a considerable extent, which means the temporal discharge fluctuations are also dampened. The various other parameters like velocity vector and pressure vector are captured for conventional and modified gate valves with different gate openings and presented in Fig. 11.

Figure 11 depicts the comparison of all these parameters for a gate opening of $25 \%(16.25 \mathrm{~mm})$. It can be observed that there are intermittent fluctuations in the mass flow rate for conventional gate valves. Whereas, in a modified gate valve, we have a constant mass flow rate even up to 500 iterations. Secondly, from the velocity and pressure vectors, a reverse flow can be distinctly observed in the case of a conventional gate valve, whereas there is no reverse flow in the case of a modified gate valve. This further emphasises that the separation zone is present in the case of a conventional gate valve and it is absent in the case of a modified gate valve. Hence, the discharge fluctuations on account of velocity fluctuations are absent in the case of the modified gate valve.

\section{Result and discussion}

Figure 4 illustrates the fluid discharge with a conventional gate valve at various rotation angles. At full opening (rotation angle $=0^{\circ}$ ), the flow rate is uniform.
However, as the rotation angle increases, the discharge becomes non-uniform due to fluid separation and the formation of eddies at the downstream of the valve between the pipe and the valve contact region with a conventional gate valve. To address this issue, a modified gate valve is developed. Figure 6 presents the fluid discharge with a modified gate valve at various rotation angles. With the modified gate valve, fluid discharge decreases uniformly as the rotation angle increases. The CFD analysis of fluid flow through a conventional and modified gate valve is shown in Fig. 10 .

\section{A. CFD analysis of pipe using conventional gate valve}

According to CFD analysis, for $100 \%$ valve opening in a conventional gate valve, streamlines are straight and fluid velocity is uniform. Wall fluid (fluid near the pipe wall) has a slightly lower velocity than core fluid (fluid flowing centrally through pipe). However, as the valve opening decreases, the velocity of the fluid suddenly increases at the valve. Fluid separation and eddy currents form at the upstream and downstream of valve for some length of pipe. For a short distance, fluid moves at high velocity in-line with the opened pipe region. However, in the eddy region, velocity drops.

Fluid pressure is higher at the inlet of the pipe and gradually decreases until it reaches the outlet of the pipe for the $100 \%$ valve opening in a conventional gate valve. However, as the valve opening decreases, the pressure of the fluid increases at the inlet and decreases at the outlet. Fluid separation occurs at the downstream of the

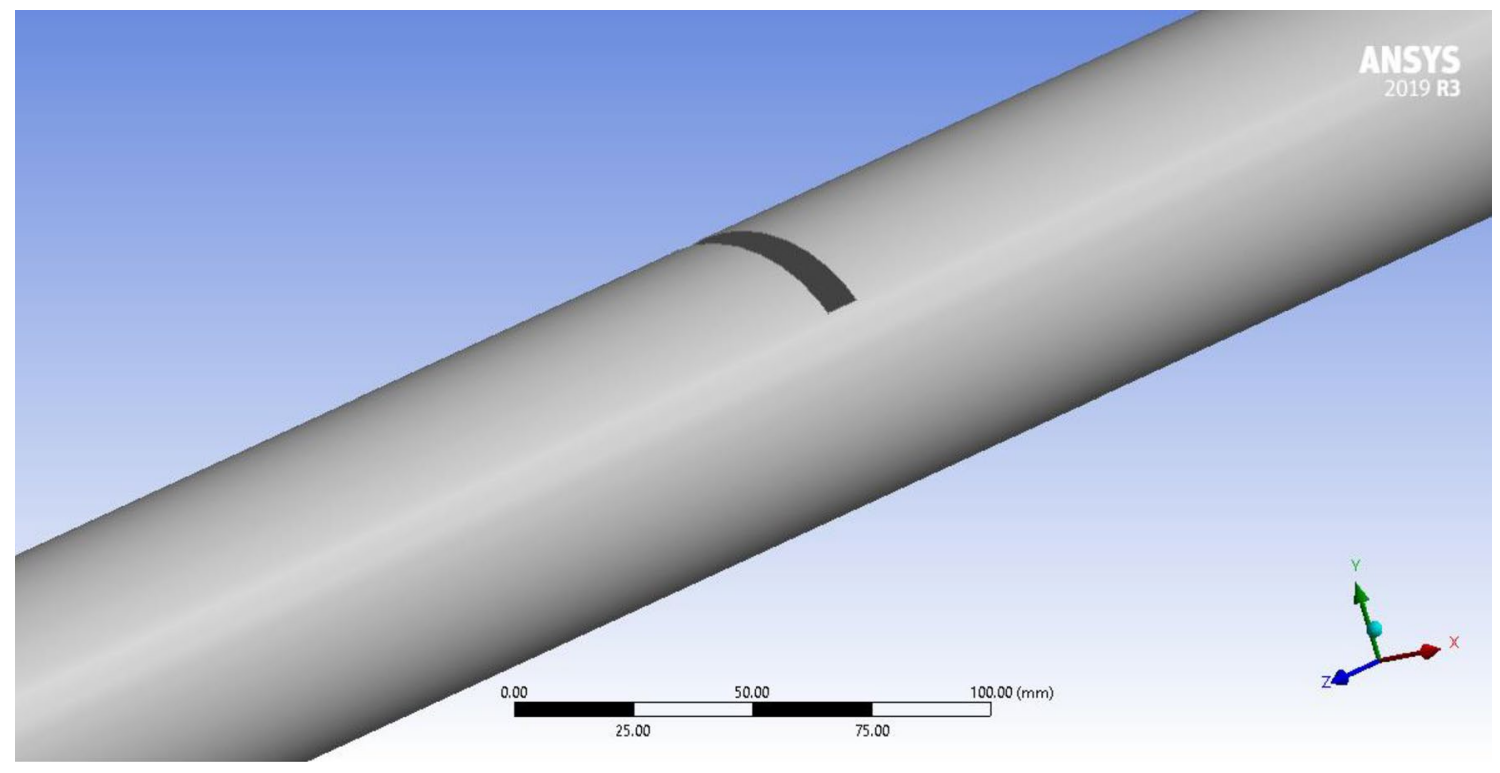

Fig. 8 Model of pipe with gate valve 

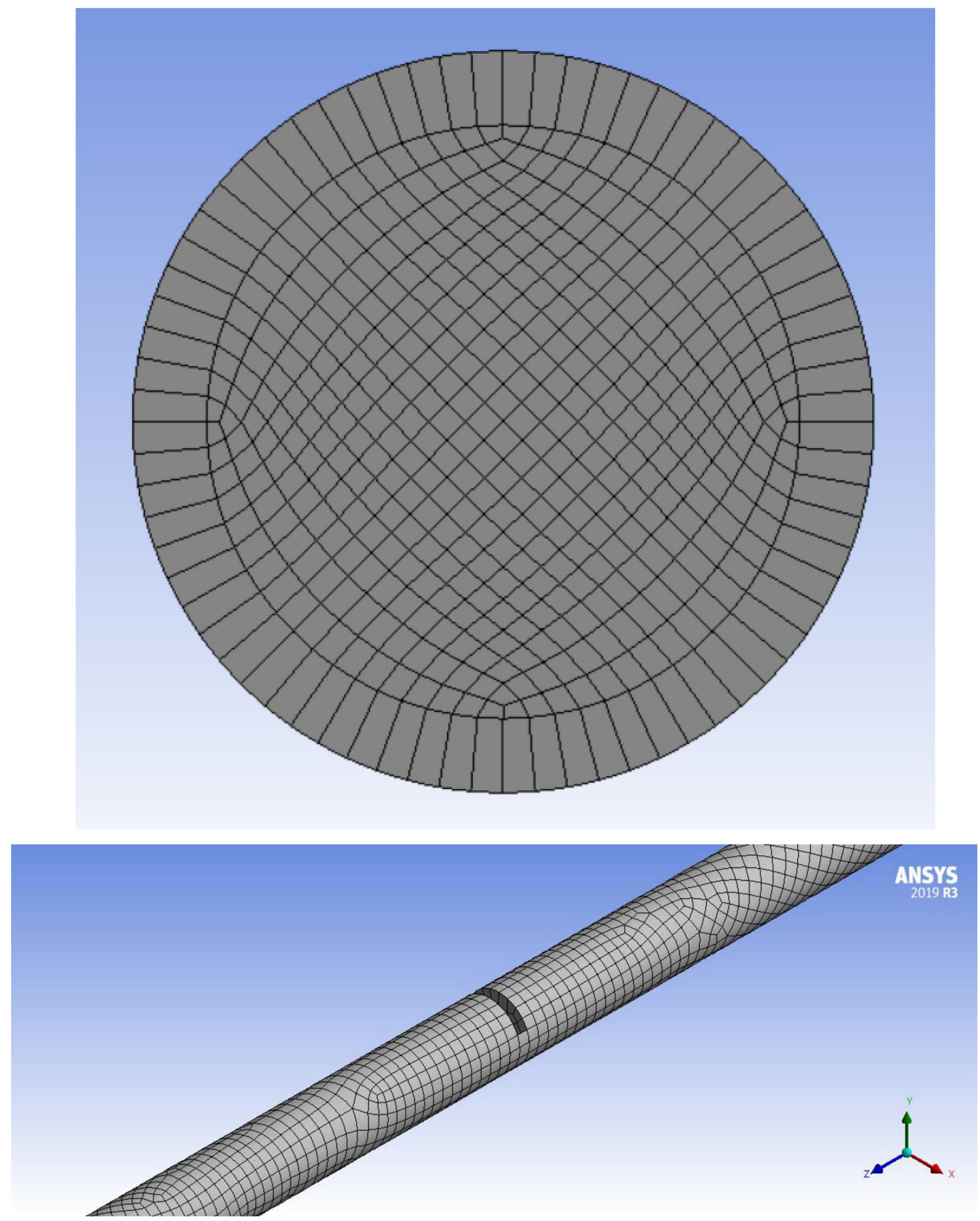

Fig. 9 Mesh Model of pipe with hexahedral element

Table 1 Input parameters for all five cases of gate opening

\begin{tabular}{llll}
\hline $\begin{array}{l}\text { Rotation angle } \\
\text { (Degree) }\end{array}$ & $\begin{array}{l}\text { Gate valve } \\
\text { opening (\%) }\end{array}$ & $\begin{array}{l}\text { Mass flow rate } \\
\text { (lps) }\end{array}$ & Velocity $(\mathrm{m} / \mathrm{s})$ \\
\hline 0 & 100 & 6.41 & 1.93 \\
1440 & 70 & 5.56 & 1.675 \\
2160 & 55 & 5.33 & 1.606 \\
2880 & 40 & 4.2 & 1.265 \\
3510 & 25 & 3.56 & 1.073 \\
\hline
\end{tabular}

valve for a certain length of pipe, resulting in frictional head loss.

\section{B. CFD analysis of pipe using modified gate valve}

When the modified gate valve is partially closed, the upper part of the rubber tube bends and acts as a nozzle. When fluid passes through a bend in a rubber tube, 
Fig. 10 a Representation of water flow through pipe by CFD analysis of pipe through (a) Conventional and (b) Modified gate vale for $100 \%, 70 \%$, $55 \%$ and $40 \%$ gate opening. $\mathbf{b}$. Mass flow rate by CFD analysis of pipe through (a) Conventional and (b) Modified gate vale for $100 \%, 70 \%, 55 \%$ and $40 \%$ gate opening (a) Flow through pipe for Conventional Gate Valve

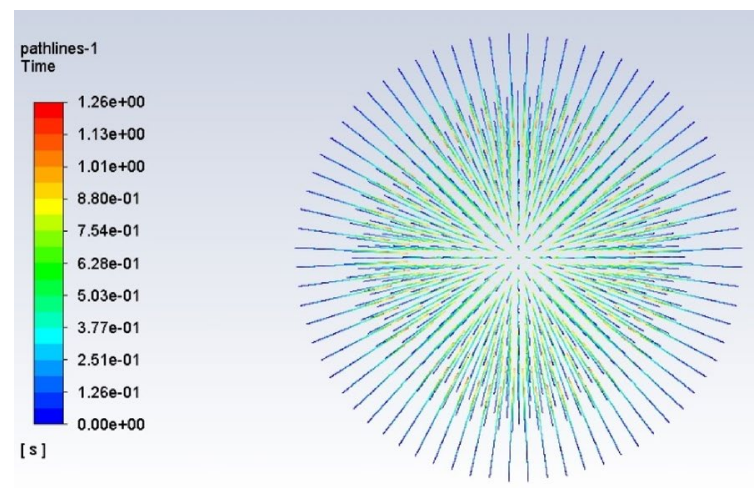

a. (i) Pipe Open $100 \%-65 \mathrm{~mm}$
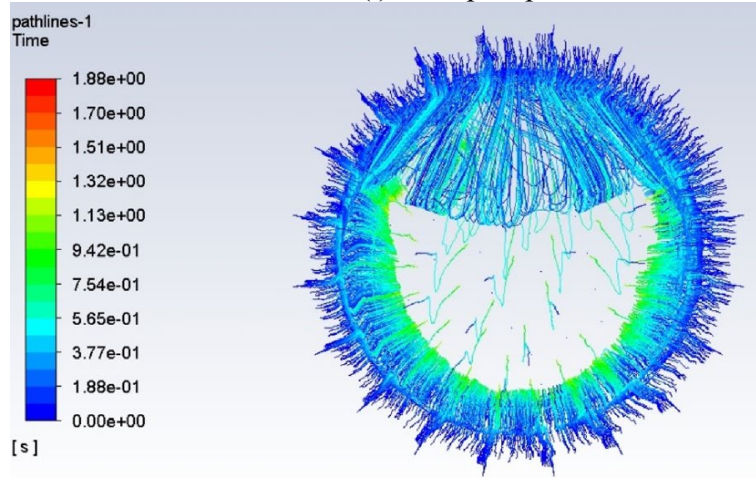

a. (ii) Pipe Open $70 \%-45.5 \mathrm{~mm}$

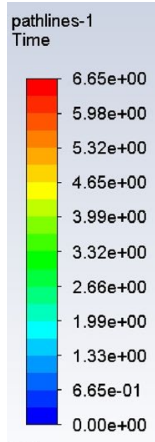

a. (iii) Pipe Open $55 \%-36.75 \mathrm{~mm}$
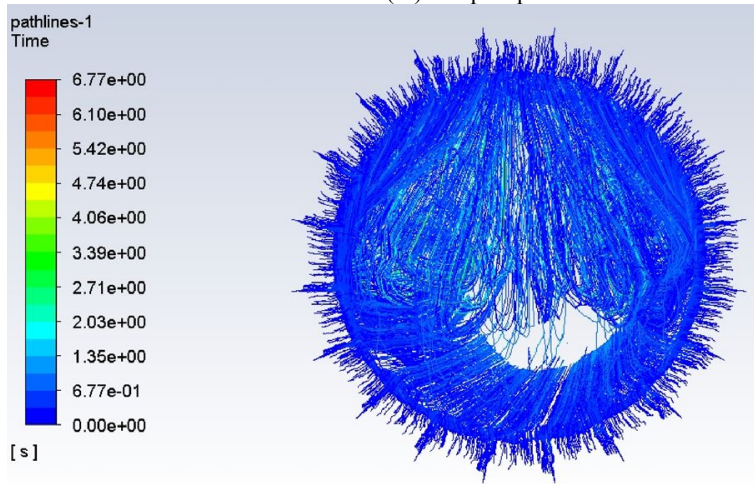

a. (iv) Pipe Open 40\% - $26 \mathrm{~mm}$

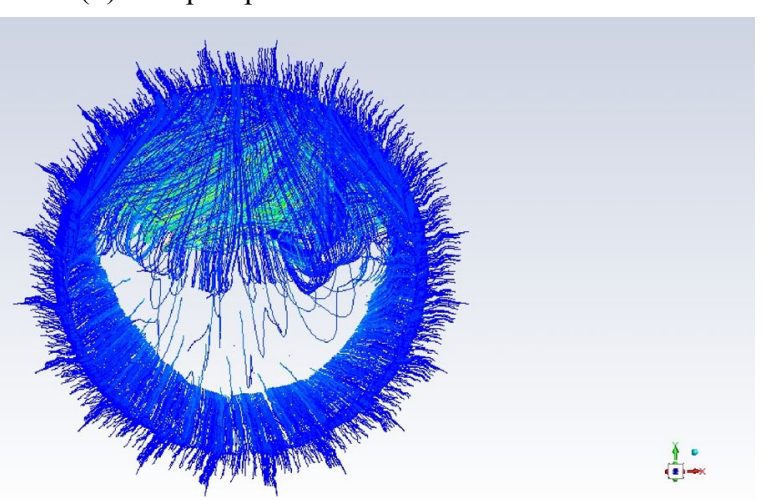

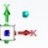

$1-$

$\therefore$


Fig. 10 (continued) (b) Flow through pipe for Modified Gate Valve

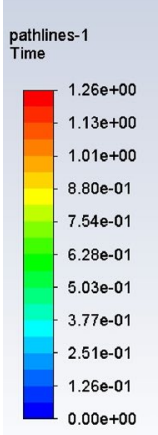

[s]

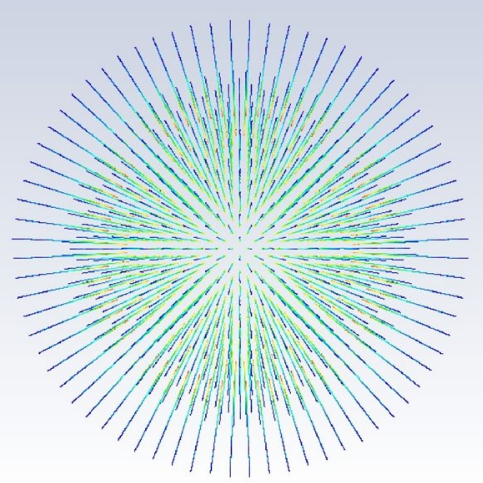

b. (i) Pipe Open $100 \%-65 \mathrm{~mm}$

pathlines-2
Time
\begin{tabular}{|l|l|}
$1.33 e+00$ \\
$1.20 e+00$ \\
$1.07 e+00$ \\
$9.34 e-01$ \\
$8.01 e-01$ \\
$6.67 e-01$ \\
$5.34 e-01$ \\
$4.00 e-01$ \\
$2.67 e-01$ \\
$1.33 e-01$
\end{tabular}
$0.00 e+00$

[s]

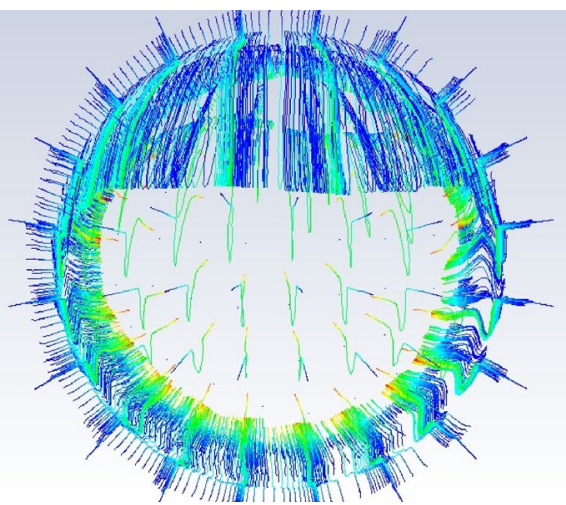

b. (ii) Pipe Open $70 \%-45.5 \mathrm{~mm}$

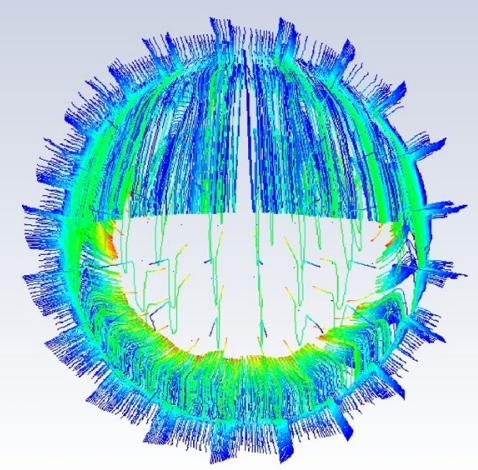

b. (iii) Pipe Open $55 \%-36.75 \mathrm{~mm}$

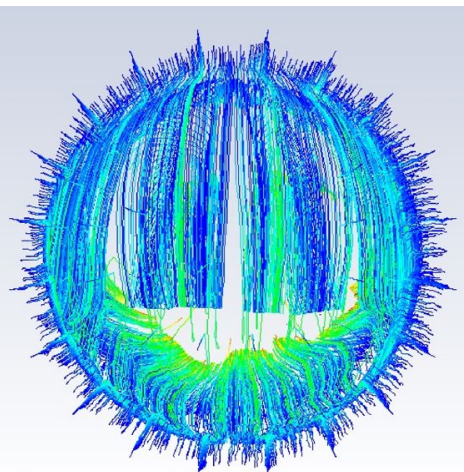

b. (iv) Pipe Open $40 \%-26 \mathrm{~mm}$ $\dot{0}$

\section{is}

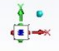

i.

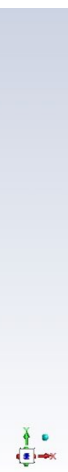

$\dot{s i n}$

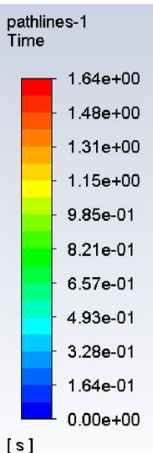


Fig. 10 (continued)

(a) Mass flow rate (Kg/s) for Conventional Gate Valve

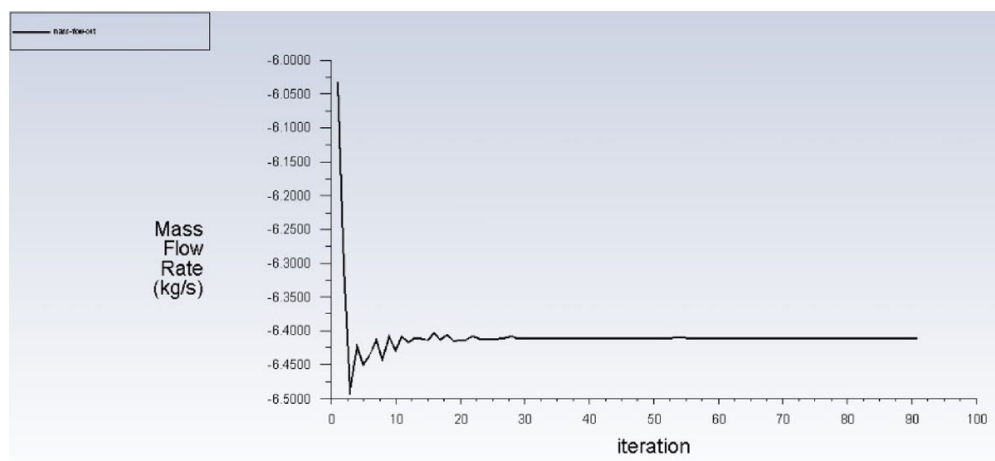

a. (i) Pipe Open $100 \%-65 \mathrm{~mm}$

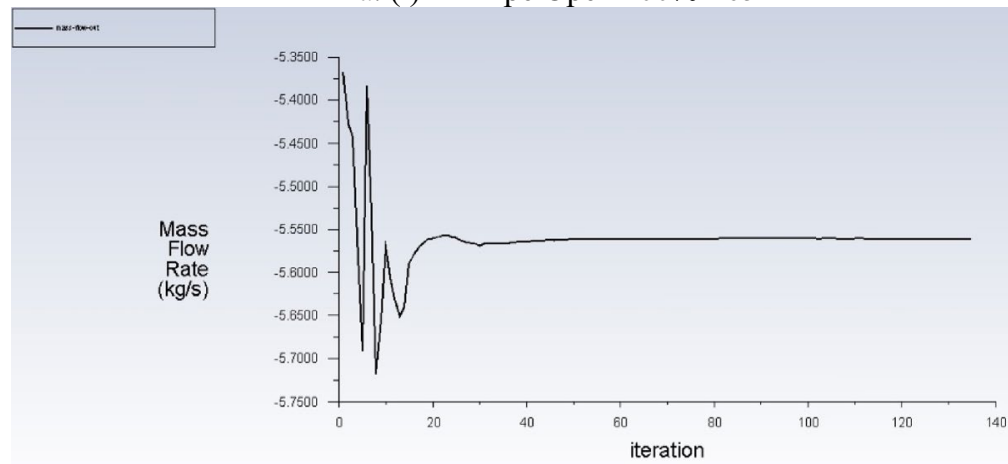

a. (ii) Pipe Open $70 \%-45.5 \mathrm{~mm}$

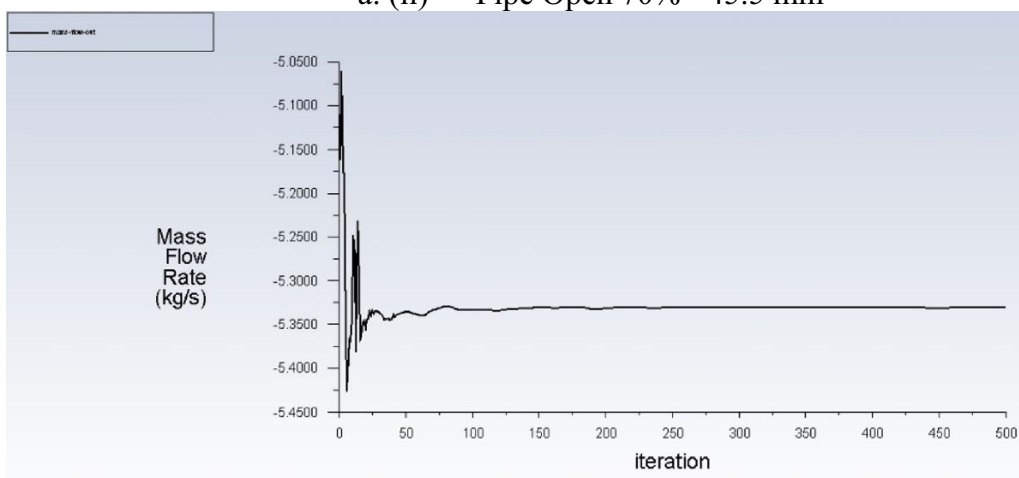

a. (iii) Pipe Open 55\% - $36.75 \mathrm{~mm}$

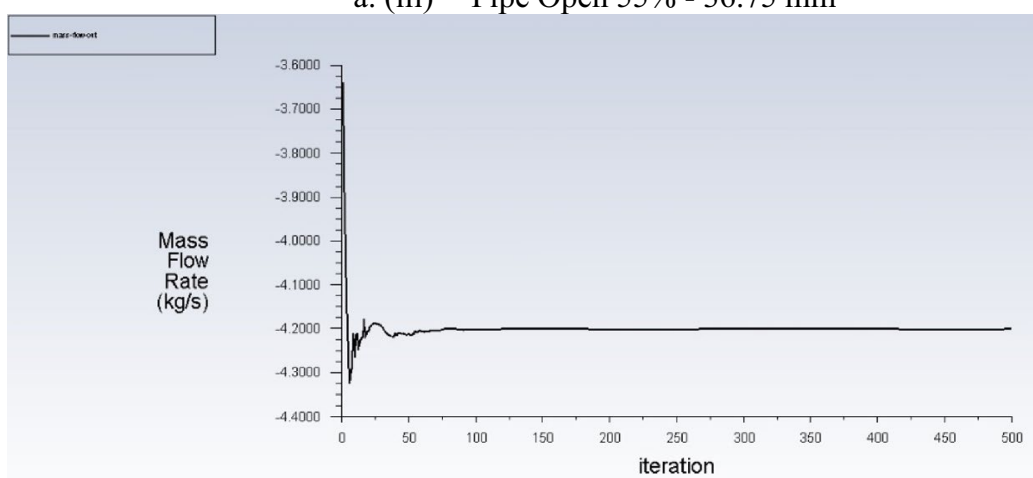

a. (iv) Pipe Open 40\% - $26 \mathrm{~mm}$ 
Fig. 10 (continued)

(b) Mass flow rate (Kg/s) for Modified Gate Valve

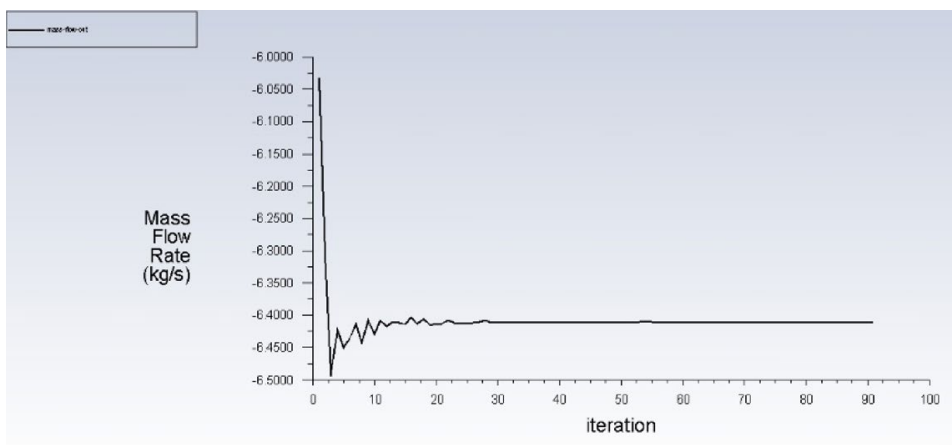

b. (i) Pipe Open $100 \%-65 \mathrm{~mm}$

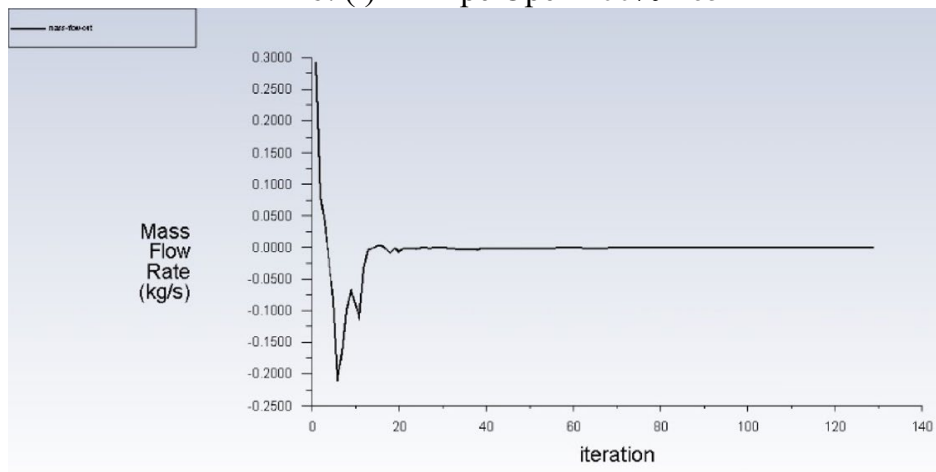

b. (ii) Pipe Open $70 \%-45.5 \mathrm{~mm}$

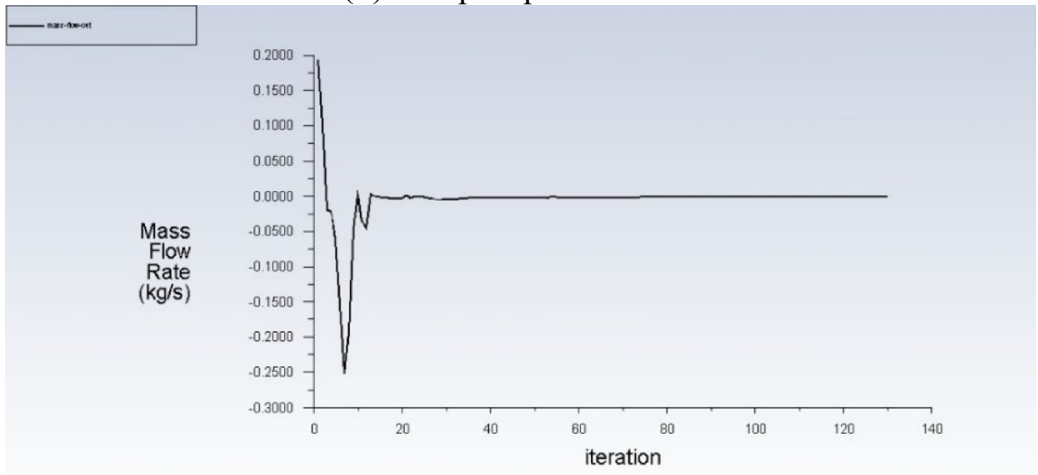

b. (iii) Pipe Open $55 \%-36.75 \mathrm{~mm}$
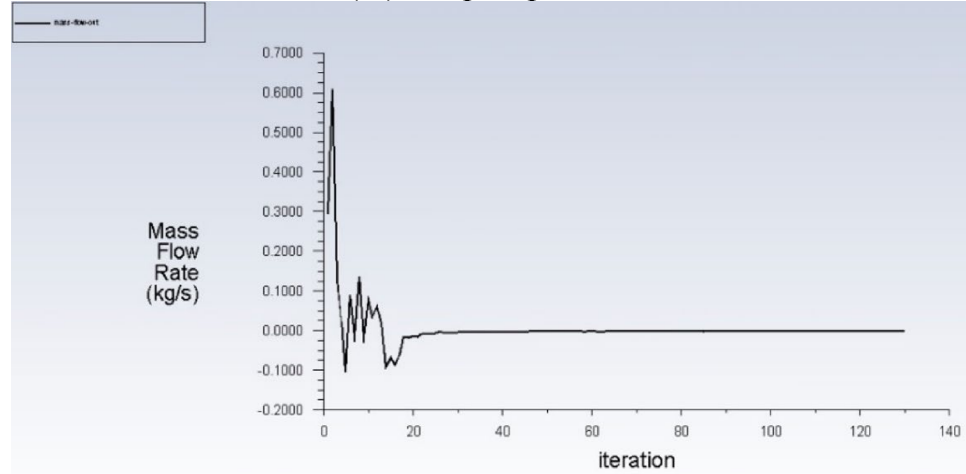

b. (iv) Pipe Open $40 \%-26 \mathrm{~mm}$ 
(a) Conventional Gate Valve

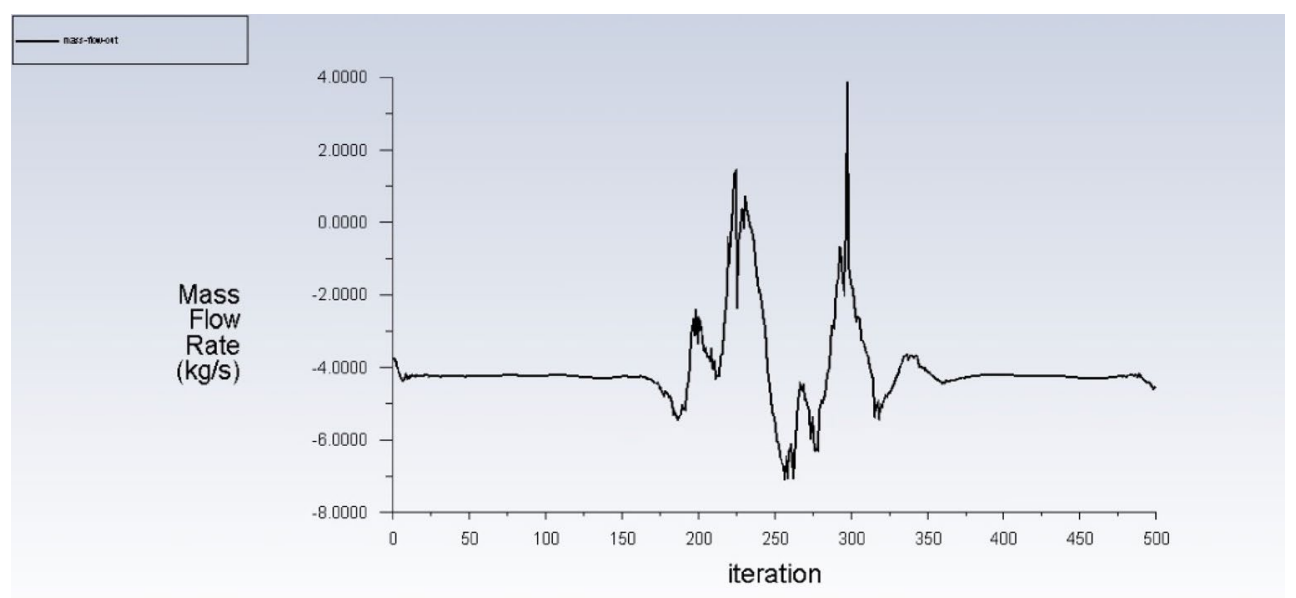

a. (i) Mass flow rate for conventional gate valve

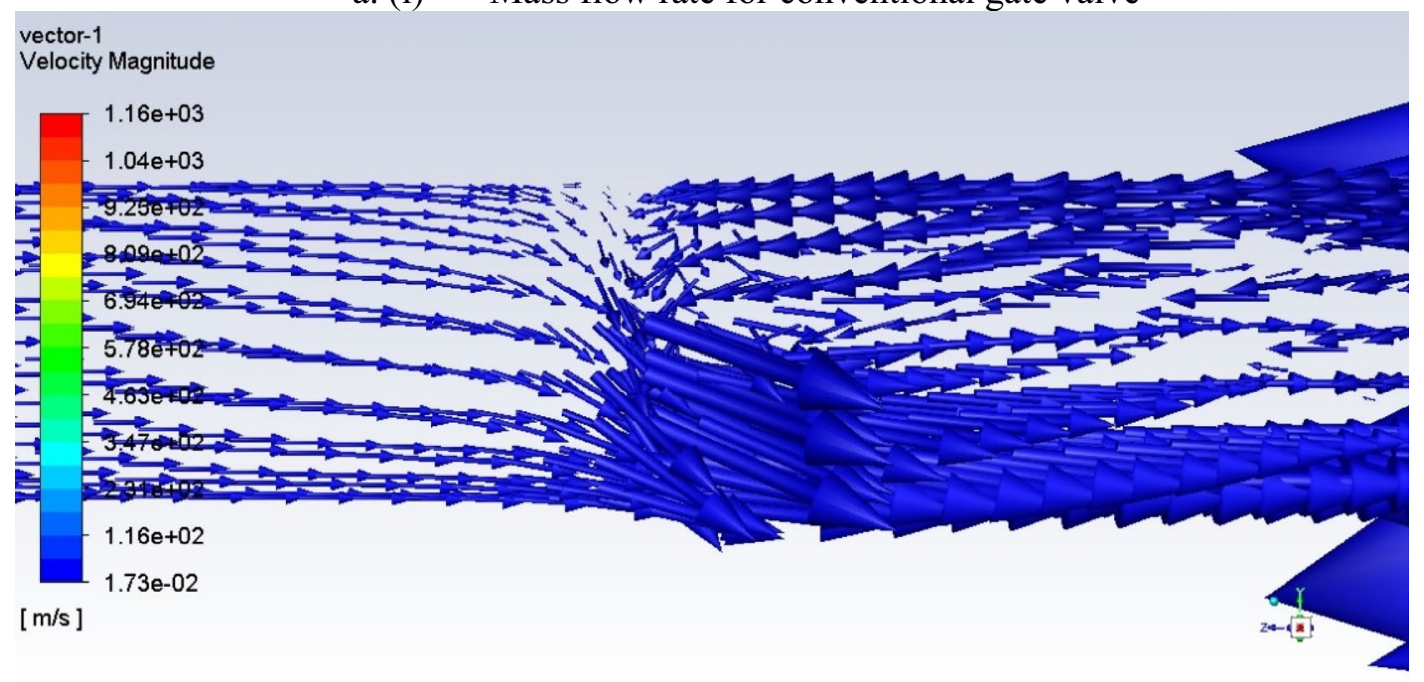

a. (ii) Velocity vector for conventional gate valve

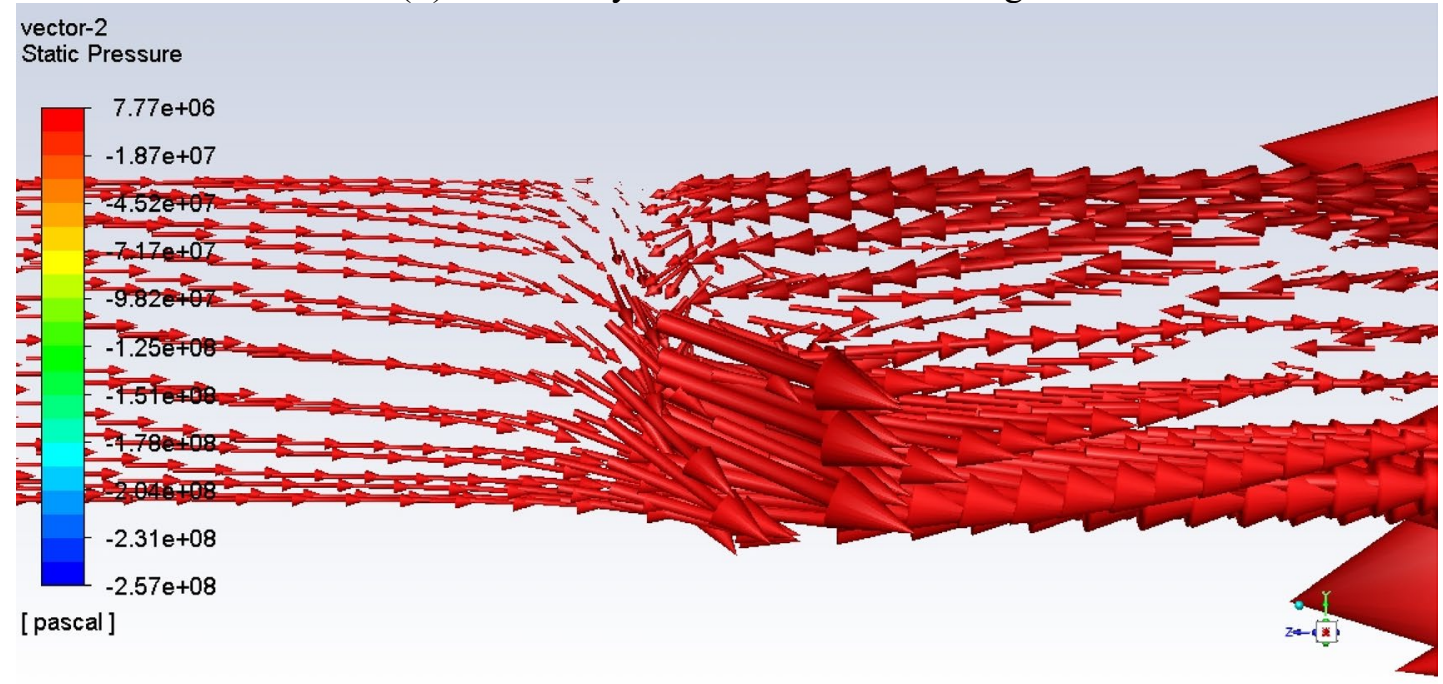

a. (iii) Pressure vector for convention gate valve

Fig. 11 Mass flow rate, velocity vector and pressure vector by CFD analysis for flow through pipe using (a) convention and (b) modified gate valve for critical $25 \%$ gate opening 
(b) Modified Gate Valve

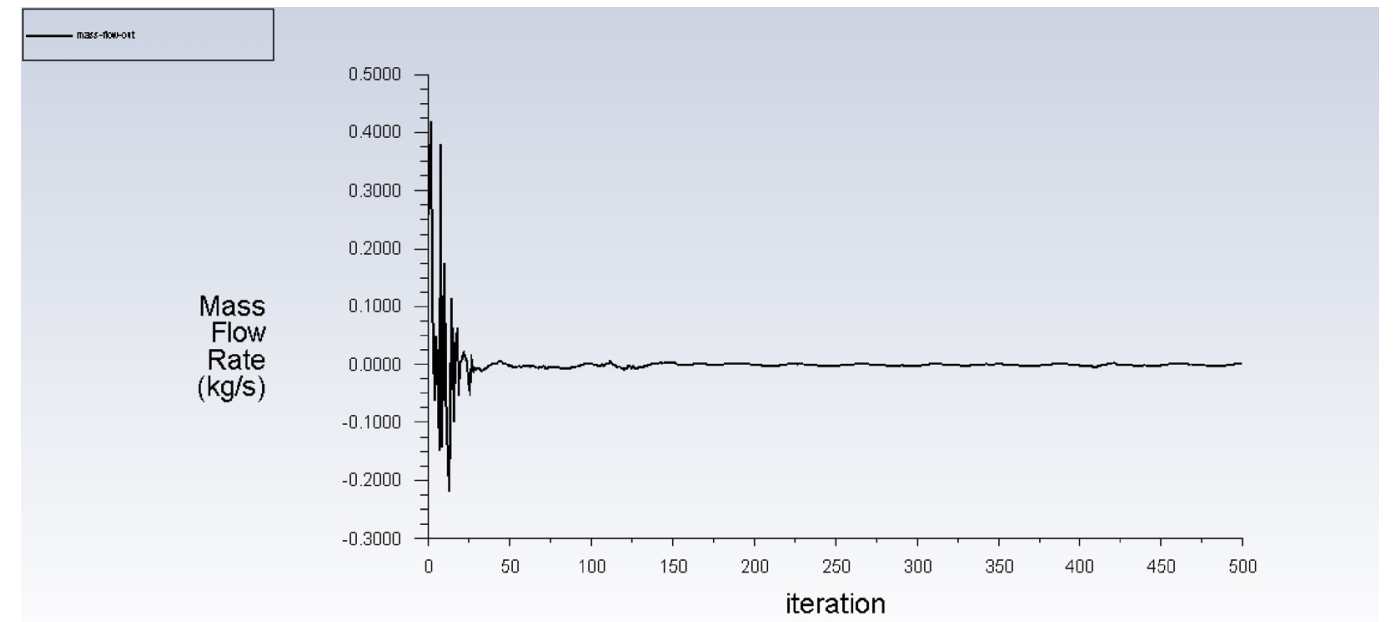

b. (i) Mass flow rate for modified gate valve

\section{vector-1}

Velocity Magnitude
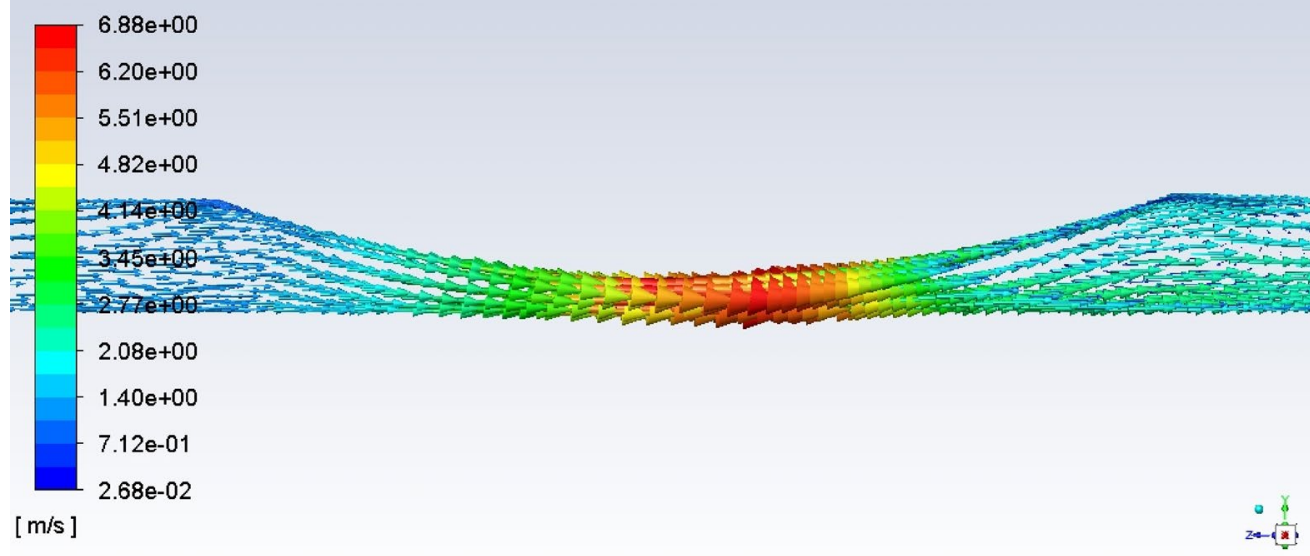

b. (ii) Velocity vector for modified gate valve

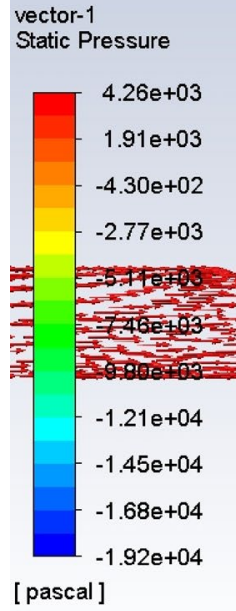

b. (iii) Pressure vector for modified gate valve

Fig. 11 (continued) 
Fig. 12 Velocity and pressure vectors of water passing through pipe for (a) Conventional and (b) modified gate valve at $100 \%, 70 \%, 55 \%, 40 \%$ Valve Opening (a) Conventional Gate Valve

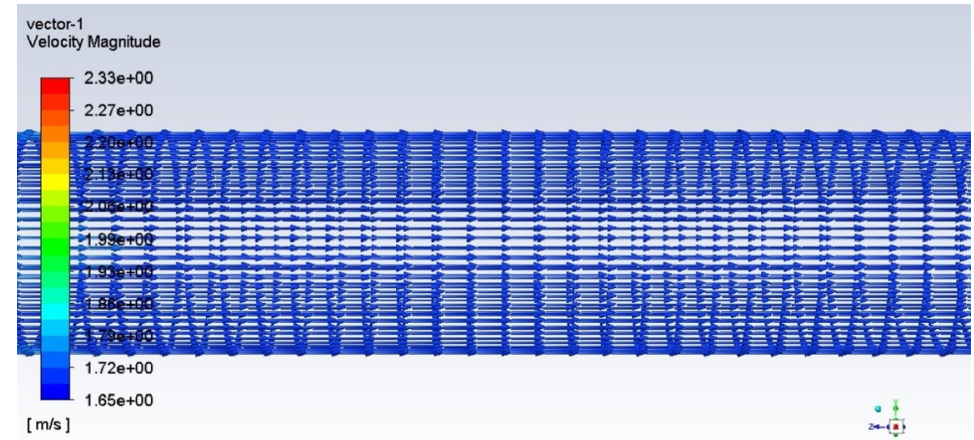

Velocity $2.33 \mathrm{~m} / \mathrm{s}$

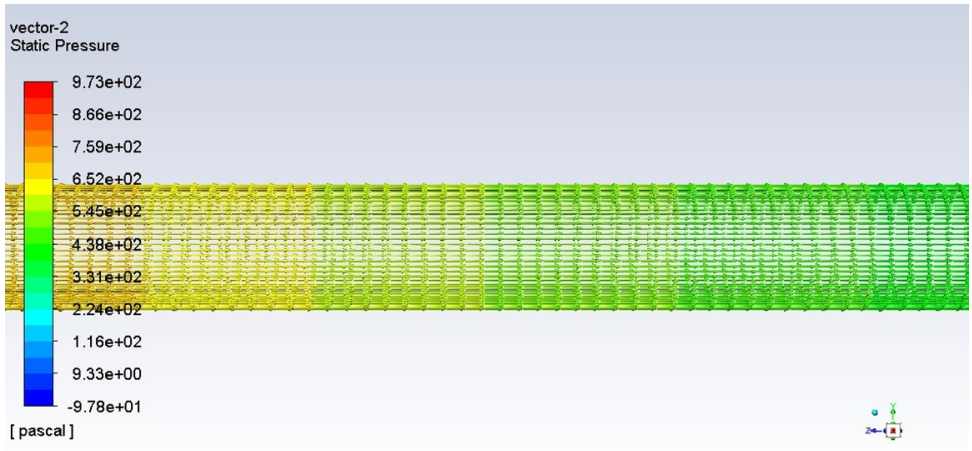

Pressure 0.00936 bar

a. (i) Velocity and Pressure vector for conventional gate valve open $100 \%-65 \mathrm{~mm}$

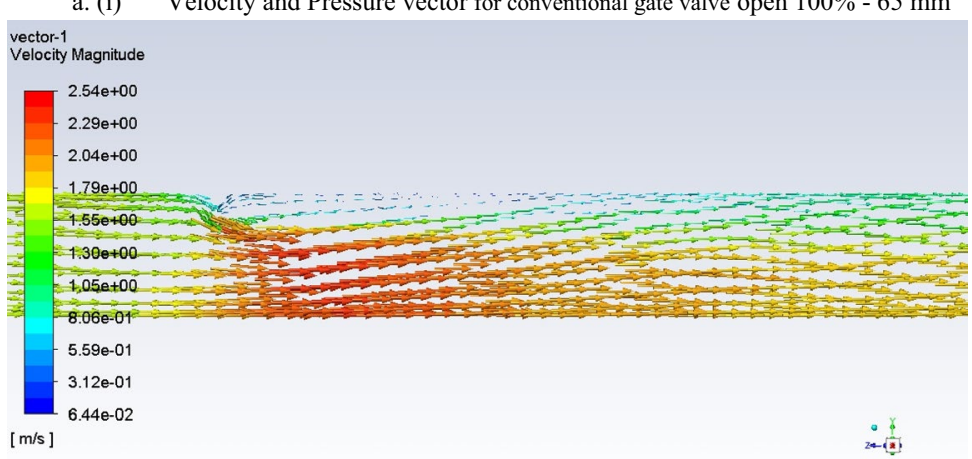

Velocity $2.52 \mathrm{~m} / \mathrm{s}$

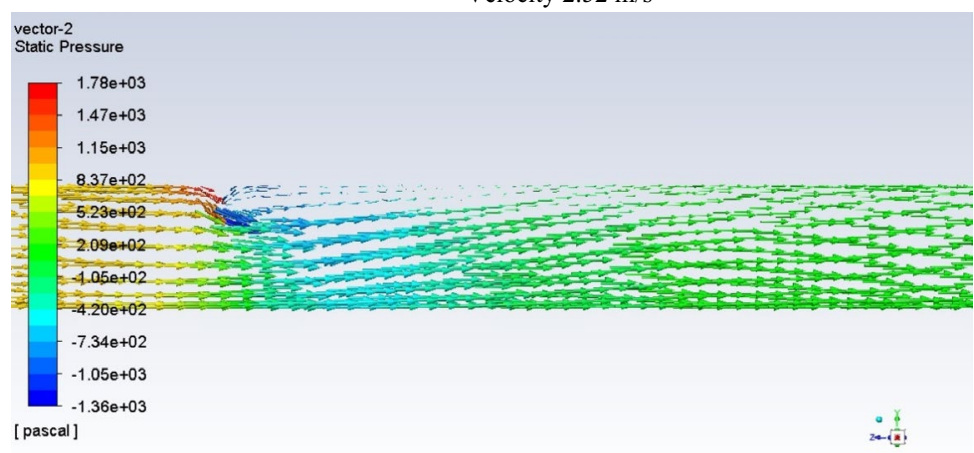

Pressure 0.0177 bar

a. (ii) Velocity and Pressure vector for conventional gate valve open $70 \%-45.5 \mathrm{~mm}$ 
Fig. 12 (continued)

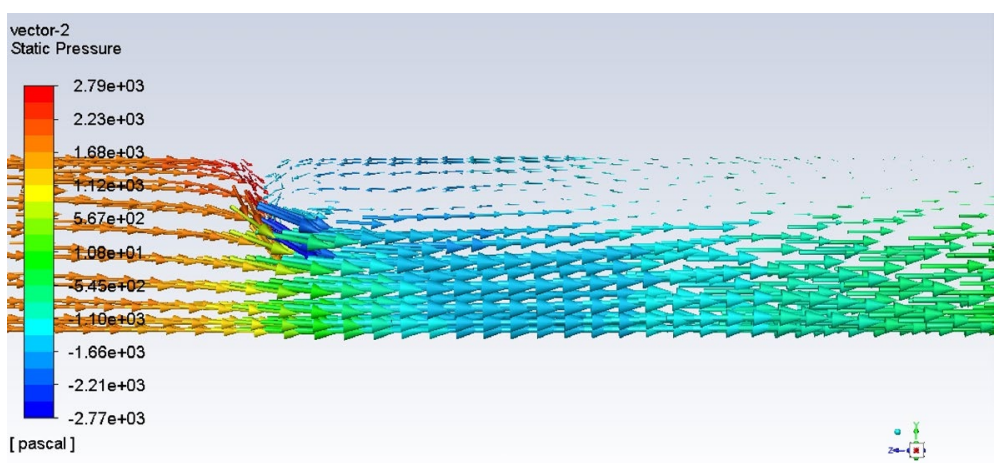

Velocity $3.08 \mathrm{~m} / \mathrm{s}$

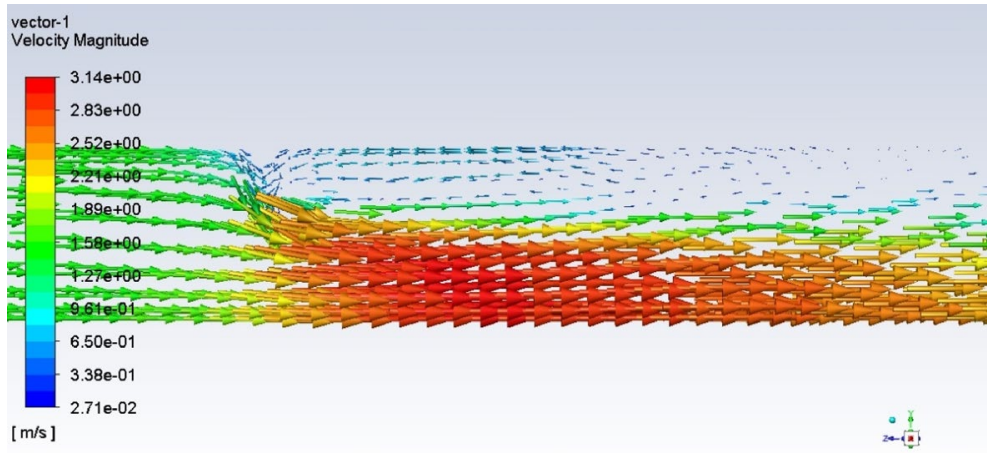

Pressure 0.0278 bar

a. (iii) Velocity and Pressure vector for conventional gate valve open $55 \%-36.75 \mathrm{~mm}$

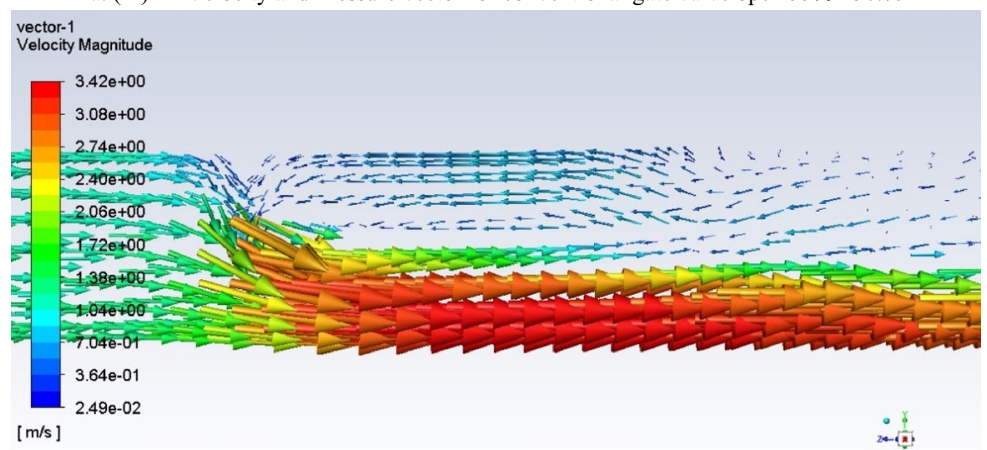

Velocity $3.325 \mathrm{~m} / \mathrm{s}$

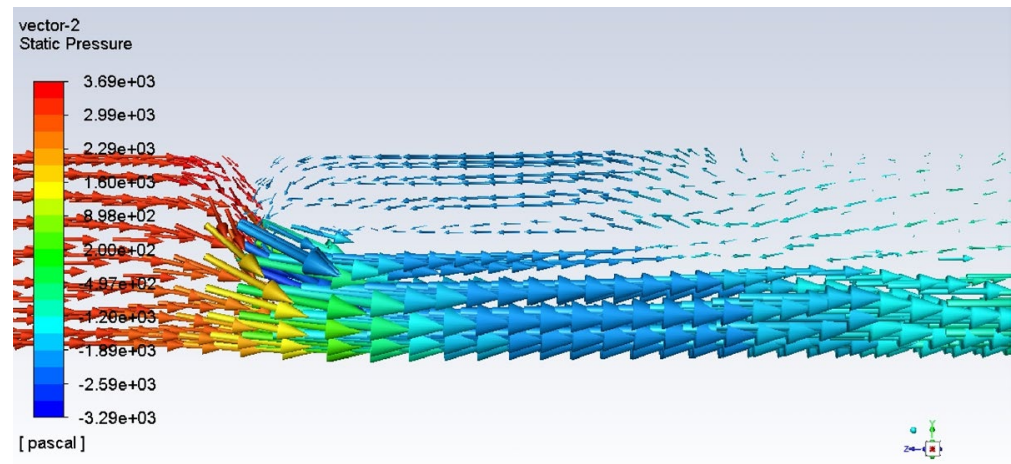

Pressure 0.0368 bar

a. (iv) Velocity and Pressure vector for conventional gate valve open $40 \%$ - $26 \mathrm{~mm}$ 
Fig. 12 (continued)

(b) Modified Gate Valve

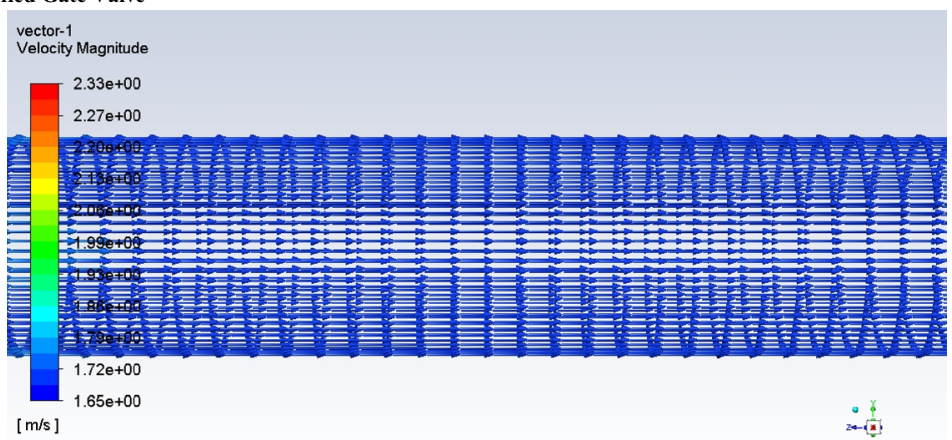

Velocity $2.33 \mathrm{~m} / \mathrm{s}$
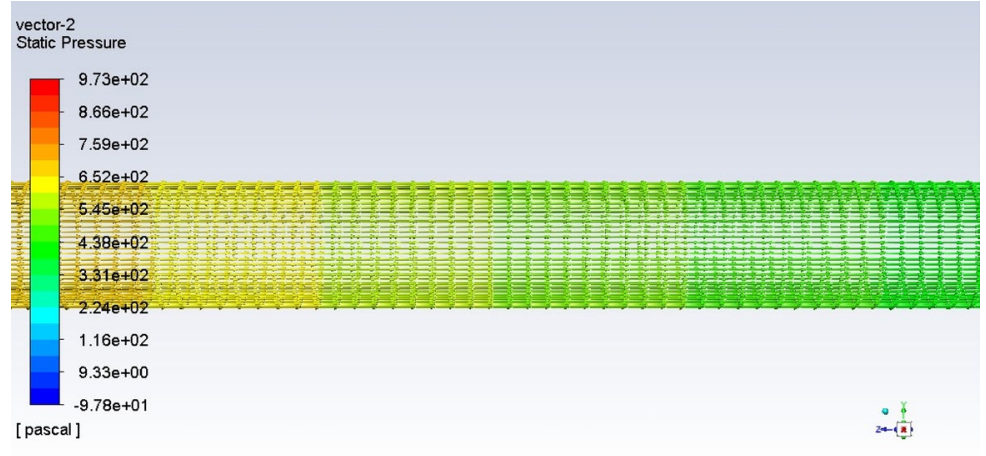

Pressure 0.00936 bar

b. (i) Velocity and Pressure vector for modified gate valve open $100 \%-65 \mathrm{~mm}$

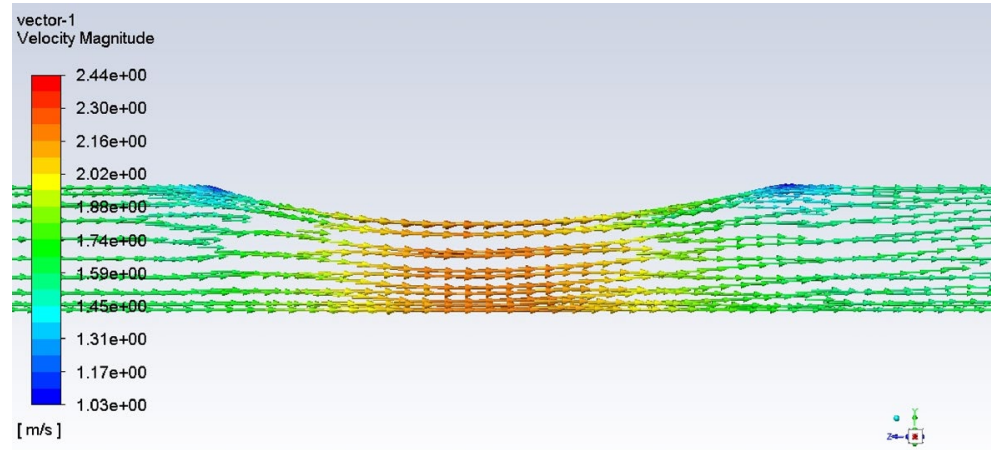

Velocity $2.43 \mathrm{~m} / \mathrm{s}$

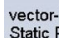

atic Pressure

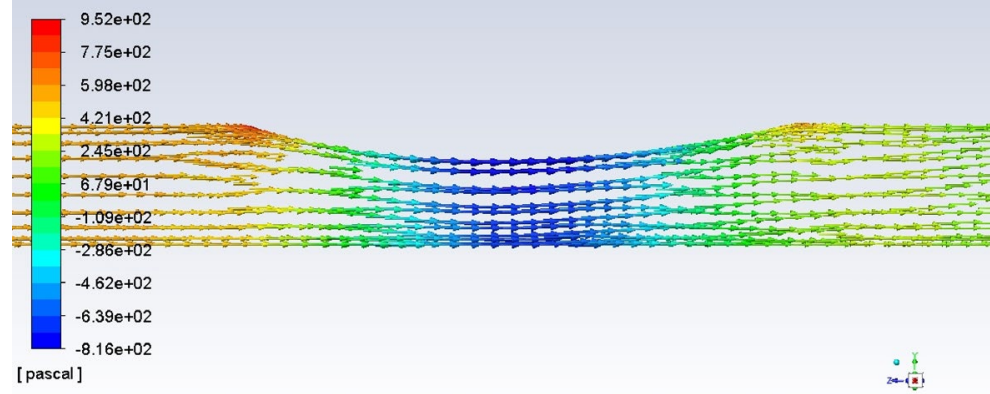

Pressure 0.00902 bar

b. (ii) Velocity and Pressure vector for modified gate valve open $70 \%-45.5 \mathrm{~mm}$ 
Fig. 12 (continued)

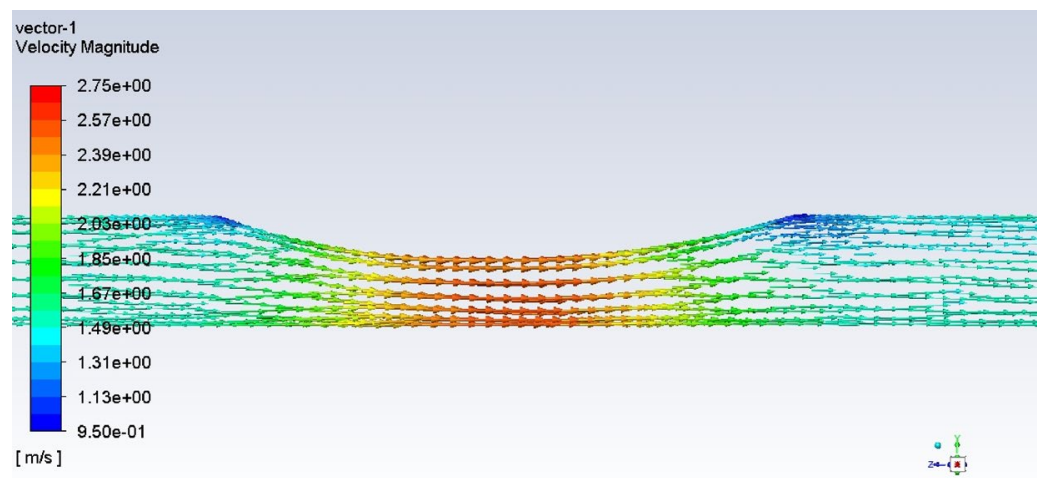

Velocity $2.74 \mathrm{~m} / \mathrm{s}$

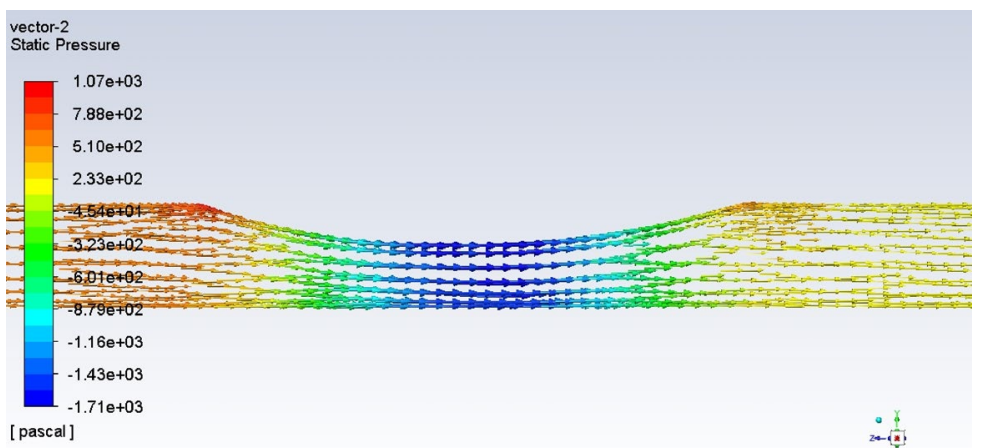

Pressure 0.01016 bar

b. (iii) Velocity and Pressure vector for modified gate valve open $55 \%-36.75 \mathrm{~mm}$ vector-1

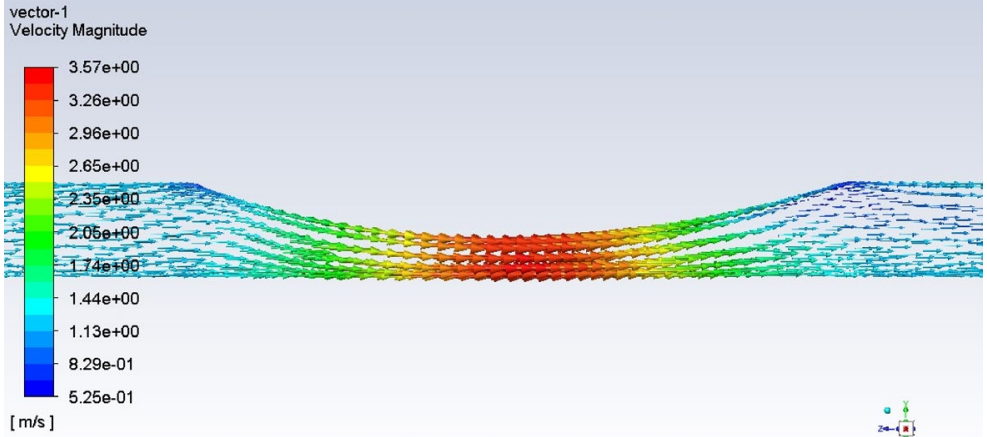

Velocity $3.56 \mathrm{~m} / \mathrm{s}$

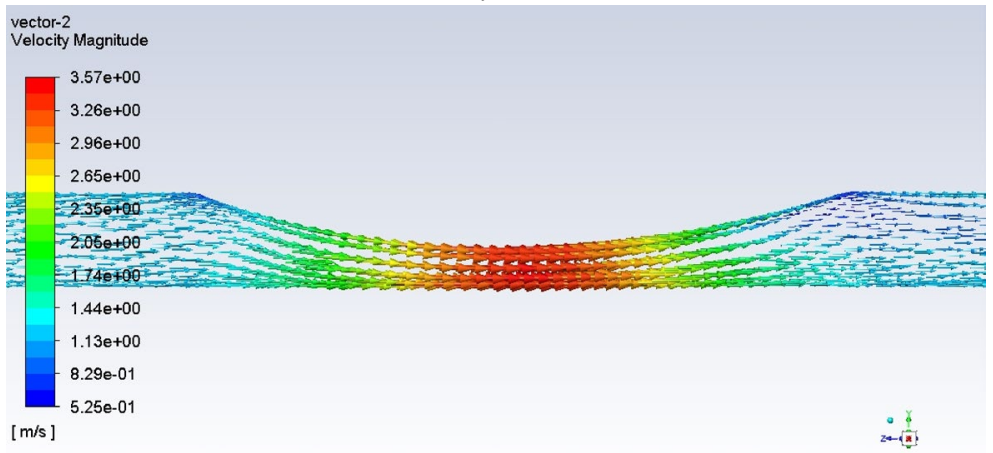

Pressure 0.0115 bar

b. (iv) Velocity and Pressure vector for modified gate valve open $40 \%-26 \mathrm{~mm}$ 
the velocity of the fluid gradually increases at the inlet of the valve, reaches a maximum value at the gate valve region, and then gradually decreases at the outlet of the valve. The pressure of the fluid gradually decreases as it approaches the upstream of the valve, reaches a minimum value at the gate valve region, and then gradually increases as it moves away from the gate valve. According to the results of this analysis, fluid separation and eddy losses can be avoided by using modified gate valves. Figure 12 shows the velocity and pressure vectors for the conventional and modified gate valves at various gate openings. It also means that the velocity and pressure of water are reduced, which causes a reduction in fluid separation and eddy losses.

Figure 10 illustrates the flow analysis of fluid through a conventional and modified gate valve. In a conventional gate valve, streamlines are straight and fluid velocity is constant when the valve is fully opened. The velocity of the fluid at the valve increases exponentially when the valve opening is reduced. For a short distance downstream and upstream of the valve, fluid separation and eddy currents develop. The velocity of fluid increases gradually as it goes over a bend in a rubber tube at the valve's input. It achieves its highest value near the gate valve, then progressively declines as it approaches the exit. Frictional head loss occurs when fluid separation occurs downstream of the valve for a given length of pipe. Fluid separation and eddy losses can be prevented by adopting modified gate valves, according to the findings of this study.

\section{Conclusion}

It is evident from the experimental study that, in the conventional gate valve, for same disc position and at different times, the discharge obtained was not same owing to formation of fluctuating separation zones and eddies. The same has also been proved by CFD studies. The separation zones could be avoided by providing a flexible membrane pipe inside the gate valve. This modification has improved the performance of gate valve and converted it into a flow measuring device. Also, CFD results are validated with the help of results of experimental study. Further, the calibration equation is valid for a constant pressure on upstream. The proposed modified gate valve has potential to replace the existing flow measuring devices such as venturi meter and orifice meter leading to considerable cost saving in various industrial applications. The use of a modified gate valve as a measuring device is restricted to a single operational condition; nevertheless, changes in operating parameters may affect the results. The usage of a modified gate valve has a variety of applications in flow rate measurement.
Being an innovative idea, it's necessary to validate it experimentally. Secondly, the concept of flow development length has been taken into consideration during experimental validation to understand the velocity distribution which varies in this part of pipe and may tend to produce variable readings of pressure and velocity. So far as commercial production of the modified valve is concerned, the flow development length can be further reduced as in this case, measurement of pressures on either side of the valve is not required for discharge calculation.

\section{Declarations}

Conflict of interest The authors declare that they have no conflict of interest.

Open Access This article is licensed under a Creative Commons Attribution 4.0 International License, which permits use, sharing, adaptation, distribution and reproduction in any medium or format, as long as you give appropriate credit to the original author(s) and the source, provide a link to the Creative Commons licence, and indicate if changes were made. The images or other third party material in this article are included in the article's Creative Commons licence, unless indicated otherwise in a credit line to the material. If material is not included in the article's Creative Commons licence and your intended use is not permitted by statutory regulation or exceeds the permitted use, you will need to obtain permission directly from the copyright holder. To view a copy of this licence, visit http://creativecommons. org/licenses/by/4.0/.

\section{References}

1. Lin Z, Ruan X-D, Zhu Z-C, Xin Fu (2014) Three-dimensional numerical investigation of solid particle erosion in gate valves. Proc IMechE Part C J Mech Eng Sci 228(10):1670-1679. https:// doi.org/10.1177/0954406213498543

2. Liu P, Liu Y, Huang Z, Cai B, Sun Q, Wei X, Xin C (2019) Design optimization for subsea gate valve based on combined analyses of fluid characteristics and sensitivity. J Pet Sci Eng. https://doi. org/10.1016/j.petrol.2019.106277

3. Kanchan M, Maniyeri R (2020) Fluid-structure interaction study and flowrate prediction past a flexible membrane using immersed boundary method and artificial neural network techniques. J Fluids Eng. https://doi.org/10.1115/1.4045575

4. Huang WX, Chang CB, Sung HJ (2012) Three-dimensional simulation of elastic capsules in shear flow by the penalty immersed boundary method. J Comput Phys 231(8):3340-3364. https:// doi.org/10.1016/j.jcp.2012.01.006

5. Maniyeri R, Suh YK, Kang S, Kim MJ (2012) Numerical study on the propulsion of a bacterial flagellum in a viscous fluid using an immersed boundary method. Comput Fluids 6291:13-24. https://doi.org/10.1016/j.compfluid.2012.03.012

6. Zhang C, Wu C, Nandakumar K (2019) Effective geometric algorithms for immersed boundary method using signed distance field. ASME J Fluids Eng 141(6):061401. https://doi.org/10. $1115 / 1.4041758$

7. Control Valve Handbook, 5th edition, Chapter 10 - Isolation valves, 187-188. Emerson Automation Solutions, Flow Controls, 
(C) 2005, 2019 Fisher Controls International LLC. D101881X012/ Sept 2019

8. Zakirnichnaya MM, Kulsharipov IM (2017) Wedge gate valves selecting essentials in pipeline systems designing based on permissible operation parameters. IOP Conf Series Earth Environ Sci. https://doi.org/10.1088/1755-1315/87/8/082055

9. Steele Jr R, DeWall KG, Watkins JC, Russell MJ, Bramwell D (1995) Gate valve and motor-operator research findings, Division of Engineering Technology, Office of Nuclear Regulatory Research U.S. Nuclear Regulatory Commission, Washington, DC, USA. https://doi.org/10.2172/106407

10. Bhilare SL, Hinge GA (2020) Conversion of gate valve into a flow measuring device. Curr Sci 119(4):691-695

11. Rambhad KS, Kalbande VP, Kumbhalkar MA, Khond VW, Jibhakate RA (2021) Heat transfer and fluid flow analysis for turbulent flow in circular pipe with vortex generator. SN Appl Sci 3:709. https://doi.org/10.1007/s42452-021-04664-8

12. Lin Z, Sun X, Tianci Yu, Zhang Y, Li Yi, Zhu Z (2020) Gas-solid two-phase flow and erosion calculation of gate valve based on the CFD-DEM model. Powder Technol 366(15):395-407
13. Palau CV, Balbastre I, Manzano J, Azevedo BM, Bomfim GV (2019) Numerical analysis of Woltman meter accuracy under flow perturbations. Water 11:1-15. https://doi.org/10.3390/w11122622

14. Žic E, Banko P, Lešnik L (2020) Hydraulic analysis of gate valve using computational fluid dynamics (CFD). Sci Rev Eng Environ Sci 89 Ser 29(3):275-288. https://doi.org/10.22630/PNIKS.2020. 29.3.23

15. Abood SA, Abdulwahid MA, Almudhaffar MA (2019) Comparison between the experimental and numerical study of (air-oil) flow patterns in vertical pipe. Case Stud Therm Eng. https://doi.org/ 10.1016/j.csite.2019.100424

16. Albaina I, Arregui FJ, Bidaguren-Alday C, Bidaguren I (2020) Influence of butterfly and gate valves upstream large water meters. Water 12:2563. https://doi.org/10.3390/w12092563

17. Wéber R, Hős C (2018) Experimental and numerical analysis of hydraulic transients in the presence of air valve. Period Polytech Mech Eng 62(1):1-9. https://doi.org/10.3311/PPme.10336

Publisher's Note Springer Nature remains neutral with regard to jurisdictional claims in published maps and institutional affiliations. 